\title{
Exploring the impact on cost and electricity production of high penetration levels of intermittent electricity in OECD Europe and the USA, results for wind energy
}

\author{
Monique Hoogwijk ${ }^{\mathrm{a}, \mathrm{b}, *}$, Detlef van Vuuren ${ }^{\mathrm{b}}$, Bert de Vries ${ }^{\mathrm{b}}$, Wim Turkenburg ${ }^{\mathrm{a}}$ \\ ${ }^{a}$ Department of Science, Technology and Society, Copernicus Institute, Utrecht University, Padualaan 14, 3584 Utrecht CH, The Netherlands \\ ${ }^{\mathrm{b}}$ Netherlands Environmental Assessment Agency (MNP), Bilthoven, The Netherlands
}

Received 17 February 2006

\begin{abstract}
In this study we explore for the USA and OECD Europe (OECD Europe includes the countries that participate in the Organisation of Economic Cooperation and Development, among which Western Europe, USA and Japan) dynamic changes in electricity production, cost and $\mathrm{CO}_{2}$ emissions when intermittent electricity sources are used with increasing penetration levels. The methodology developed can be applied for both solar photovoltaic (PV) and wind energy. Here the focus of the results is on penetration of wind electricity in the electricity system as simulated in a long-term model experiment in which the electricity demand is kept constant over time. All important parameter are included in a sensitivity analysis. With increasing penetration levels the cost reduction of wind electricity caused by upscaling and technological learning is counteracted by the cost increase due to (1) the need for additional back-up capacity, (2) the need to generate wind electricity at less favourable sites, and (3) discarded wind electricity because of supply-demand mismatch. This occurs after about $20 \%$ wind electricity production as percentage of current electricity production. At this level about 500 (OECD Europe) and 750 (USA) $\mathrm{TWh} \mathrm{yr}^{-1}$ wind electricity is absorbed in the system with the electricity demand of the year 2000. Wind electricity is found to be discarded when the production is about 55 (USA) to 10 times (OECD Europe) the present electricity produced from wind power. Beyond $30 \%$ of present electricity production, cost increases most significantly because of discarded wind electricity, excluding storage. In both regions the use of wind electricity would mainly avoid use of natural gas. The $\mathrm{CO}_{2}$ emissions abatement costs range from 14 (OECD Europe) to 33 (USA) \$ per ton $\mathrm{CO}_{2}$ differ in both regions due to a faster wind electricity cost increase in OECD Europe.

(C) 2006 Elsevier Ltd. All rights reserved.
\end{abstract}

Keywords: Intermittency; Wind energy

\section{Introduction}

The geographical and technical potential to generate electricity from intermittent renewable energy sources such as wind turbines and solar photovoltaic (PV) systems, are much larger than current total electricity consumption, even excluding offshore locations [1,2]. For wind energy it is found that currently a significant part of the technical potential can be produced at cost levels nearly competitive with present conventional electricity production. $R \& D$ and

\footnotetext{
*Corresponding author. Ecofys Netherlands BV, P.O. Box 84083503 RK Utrecht, The Netherlands. Tel.: + 31302807823 ; fax: +31302808301 .

E-mail address: M.Hoogwijk@Ecofys.nl (M. Hoogwijk).
}

experience with expanding capacity may reduce these costs further. For grid connected solar PV, electricity production costs could in the long term come down to competitive levels for sites with significant solar irradiance, depending on the costs of conventional power production $[3,4]$.

These conclusions are drawn from regional and global static cost-supply curves for wind and solar PV electricity. ${ }^{1}$ However, when considering competitiveness with other electricity sources at longer timeframes and integrated in an electricity system, static on-site cost-supply curves are not sufficient. First, because increased use of wind and solar PV

\footnotetext{
${ }^{1}$ These on-site production costs are here referred to "electricity production costs', compared to the 'overall electricity production costs', which include the additional costs of integration in the electricity system.
} 
leads to reductions of the electricity generation costs due to learning-by-doing, upscaling and mass production. Second, because wind and solar PV and uncontrollable by nature, the supply from wind turbines demands additional system configurations and operation and, therefore additional costs. Clearly, a key factor here is that the time and duration of electricity supply from wind and solar sources are outside the control of the system operator. Furthermore, the cost of conventional sources may also change due to, for instance, technological development or depletion.

At present the solar PV capacity connected to grids world-wide is small, maybe 0.5 or $1 \mathrm{GW}$ in total. For wind turbines, this figure is over $30 \mathrm{GW}$. Wind electricity already has significant shares in the electricity supply in some countries, e.g., about $17 \%$ in Denmark [5], or in parts of countries, e.g., 25\% in Schleswig-Holstein [6]. Such high penetrations require technical adaptations such as additional back-up capacity or transmission capacity [7]. If wind and solar PV would penetrate at the levels simulated in some future energy scenarios, such as RIGES [8], FFES [9] and SRES [10], significant adaptations to the planning and operational strategy of the electricity system will be needed. The most important ones include the need for spinning reserve capacity, back-up capacity (especially load-following or storage capacity) and transmission capacity. These influence the overall production costs of electricity from intermittent sources. They are also important for the estimation of the $\mathrm{CO}_{2}$ abatement costs for wind and solar PV technologies.

The objective of this study is to explore on a regional scale, i.e. the USA and OECD Europe, the dynamic changes in electricity production and $\mathrm{CO}_{2}$ abatement costs as function of the penetration of intermittent electricity sources. In our study, the following questions are of special interest: Which factors determine the overall electricity production costs of wind and solar PV electricity with increasing penetration? What is the effect of the depletion of wind and solar PV resources (i.e. the generation of wind and solar PV at less favourable sites) with increasing penetration? At which penetration levels wind and/or solar PV electricity has to be discarded? What are the overall electricity production costs of wind power with increasing penetration? Which fuels are saved by the introduction of wind in the electricity system and how much $\mathrm{CO}_{2}$ emissions can be reduced at what costs?

This type of analyses has been done before for strictly defined electricity systems and/or at a national level, e.g., [11-13]. However, the number of studies dealing with these questions for the long term and large regions is small [14]. In our study we focus on the regional level to make the results applicable for global energy scenarios. The analysis is done using data on electric power production of the regional energy model TIMER 1.0 developed at the RIVM, the Netherlands [15]. Also, we use a new electricity module based on the Load Duration Curve called EPG (Electric Power Generation) that has been developed recently as part of the TIMER 2.0 model [16]. The model uses regional cost-supply curves of wind and solar PV electricity from earlier studies, [1,2]. We do not analyse full scenarios for regional electricity demand and supply developments, but instead present a simulation experiment with constrained parameter settings as these issues can better be 'controlled' i.e. analysed for sensitivity. These constrained parameters settings include:

- Electricity demand is kept constant as a function over time. This implies that new capacity is installed only when old capacity has to be replaced.

- Fuel costs of coal, oil, gas and biomass and specific investment costs of related power plants are kept constant over time.

- Wind capacity is given a desired fraction of the total capacity, up to $50 \%$ penetration (in terms of capacity) using two penetration paths.

In this study we focus on wind electricity production mainly. To assess fuel and $\mathrm{CO}_{2}$ savings we have run the electricity model over 50 years (2000-2050) with no additional wind capacity and have compared the results with a run where wind capacity is added. The regions USA and OECD Europe have been chosen as they have a significant technical potential of wind electricity and relatively good data availability.

In our study we distinguish two penetration paths. In the first one (Experiment A) the intermittent capacity is assumed to penetrate to $50 \%$ share on capacity basis in 2050 with $1 \%$ growth each year, starting with $1 \%$ capacity share in 2001. The second one (Experiment B) includes a time path and is based on present installed capacities in the USA and OECD Europe and the targets for wind capacity installed in the year 2010 and/or 2020 formulated by the American and European Wind Energy Association, i.e. $30 \mathrm{GW}$ in 2010 for the USA [17] and $75 \mathrm{GW}$ in 2010-180 GW in 2020 for OECD Europe [18]. For the remaining years, we assumed an exponential growth of $8 \%$ for $2010-2050$ in the USA and 3\% for the period 2020-2050 for OECD Europe. The total amount of capacity of the system is not increased, but the desired capacity is only installed if there is a demand for replacement capacity.

This study is structured as follows. First, the static costsupply curves of wind and solar PV are given and extended with transmission costs. Also monthly fluctuation characteristics are presented (Section 2). Next, Section 3 focuses on the technical aspects and cost implications of high penetrations of intermittent sources. In Section 4 we describe the model used to investigate technical, environmental and economic aspects of the penetration of wind and solar PV power into regional electricity systems, while Section 5 presents the results of the model experiments for wind electricity. The sensitivity for key parameters of wind electricity is investigated in Section 6, followed by a discussion in Section 7 and a summary and conclusions in Section 8. 
Table 1

The total electricity demand as simulated by the TIMER 1.0 model for the year 2000 and the technical potential of wind electricity and solar PV electricity

\begin{tabular}{llllll}
\hline & $\begin{array}{l}\text { Electricity demand } \\
\left(\mathrm{GWh} \mathrm{yr} \mathrm{km}^{-2}\right)^{\mathrm{a}}\end{array}$ & $\begin{array}{l}\text { Wind electricity } \\
\text { potential } \\
\left(\mathrm{GWh} \mathrm{yr} \mathrm{km}^{-2}\right)\end{array}$ & $\begin{array}{l}\text { Wind electricity } \\
\text { potential } \\
\left(\mathrm{PWh} \mathrm{yr}^{-1}\right)^{\mathrm{b}}\end{array}$ & $\begin{array}{l}\text { Solar PV electricity } \\
\text { potential } \\
\left(\mathrm{GWh} \mathrm{yr}^{-1} \mathrm{~km}^{-2}\right)\end{array}$ & $\begin{array}{l}\text { Solar PV electricity } \\
\text { potential } \\
\left(\mathrm{PWh} \mathrm{yr}^{-1}\right)\end{array}$ \\
\hline USA & 0.4 & 2.2 & 21 & 1.3 & 15 \\
OECD Europe & 0.8 & 1.1 & 4 & 0.8 & 4 \\
\hline
\end{tabular}

${ }^{\mathrm{a}} \mathrm{GWh}=10^{6} \mathrm{kWh}$.

${ }^{\mathrm{b}} \mathrm{PWh}=10^{12} \mathrm{kWh}$.

\section{Regional static cost-supply curves of wind and solar PV}

As a starting point we use the regional cost-supply curves of onshore centralised wind and solar PV electricity presented in $[1,2] .^{2}$ The yearly average technical potentials represented by these curves ${ }^{3}$ are recalculated at a monthly level, using the variation of the wind and solar resources as presented in [19-21]. Both the electricity demand per $\mathrm{km}^{2}$ as simulated by the TIMER 1.0 model (see Section 4) for the year 2000 and the technical potential of wind electricity and solar PV electricity (independent of costs) are given in Table 1. It shows that the demand density is lower in the USA compared to OECD Europe. As the supply density is higher in the USA, it can already be expected that the impact of depletion with increasing penetration is less severe than in OECD Europe.

The resulting monthly values of the technical potential at $2 \$ \mathrm{kWh}^{-1}$ cut-off on-site generation costs for the two regions are given in Fig. 1. The cut-off level implies that if the on-site generation costs exceed $2 \$ \mathrm{kWh}^{-1}$, it is assumed that there is no potential. This is only done because of representation of cost supply curves. There are considerable variations in supply: for wind the difference between the highest and lowest month can be a factor 3, and for solar PV more than a factor 5. For wind, the technical potential of electricity supply is $21 \mathrm{PWh} \mathrm{yr}^{-1}$ for the USA and $4 \mathrm{PWh} \mathrm{yr}^{-1}$ for OECD Europe. For solar PV it is $15 \mathrm{PWh} \mathrm{yr}^{-1}$ for the USA and $4 \mathrm{PWh} \mathrm{yr}^{-1}$ for OECD Europe. It should be noted that the electricity consumption in the year $2000^{4}$ in the USA was about $4.0 \mathrm{PWh} \mathrm{yr}^{-1}$ and in OECD Europe 2.8 $\mathrm{PWh} \mathrm{yr}^{-1}$.

For both wind and solar $\mathrm{PV}^{5}$ Fig. $2 \mathrm{a}$ and $\mathrm{b}$ show the cost distribution of on-site electricity production within the two

\footnotetext{
${ }^{2}$ Note that we excluded offshore wind electricity, we included centralised PV systems only, as these systems are more comparable in terms of investment strategy to conventional plants than decentralised systems. In [1], the estimated cost-supply curve of solar PV electricity consists mainly of centralised systems, so this restriction does not influence the results in the experiments conducted here.

${ }^{3}$ The technical potential has been calculated at grid cell level, at $0.5^{\circ} \times 0.5^{\circ}$ accounting for the spatial distribution of the climate and landuse changes.

${ }^{4}$ See BP statistics, available at www.BP.com.

${ }^{5}$ The costs of wind power are based on an average turbine size of $1 \mathrm{MW}$, total specific investment costs of about $1170 \$ \mathrm{~kW}^{-1}$ and a load factor that depends on the wind speed. For a wind speed of $7 \mathrm{~m} \mathrm{~s}^{-1}$ at hub height, a load factor of about 0.25 is assumed [2]. For solar PV systems the
}

regions. In this figure also the areas that are excluded for wind or solar PV electricity production are indicated, as discussed in [1,2]. In the USA, there is one large area (Great Plains) where wind power may be produced at relatively low cost. In OECD Europe, the low cost sites are more spread. For solar PV electricity, significantly higher generation costs are found and the geographical distribution is different.

The cost-supply curves of on-site electricity produced by wind turbines and solar PV systems are shown in Fig. 3. A difficult problem is to estimate the additional costs for connection to electric power networks, as we have no detailed information on grid characteristics or load centres-let alone their changes over time. We have chosen a simplified approach to estimate transmission costs. First, we estimate the electric load demand in the $0.5^{\circ} \times 0.5^{\circ}$ grid cells, by allocating the regional electricity use from the TIMER 1.0-model proportional to the population density in the year 2000 from the IMAGE 2.2 model [22]. The second step is to postulate a critical value of the load at which a grid cell can be considered to have an electricity grid; in this case the cell is designated a load centre. The transmission distance to a load centre is assumed to be equal to the radius from a grid cell to its neighbouring cells for which the sum of the electricity demand in these cells equals or exceeds the critical value. This critical value is chosen equal to the supply of electricity that can be expected from a power plant of $50 \mathrm{MW}$ with a load factor of $0.8 .^{6}$ An estimated distance of e.g., $40 \mathrm{~km}$ means that within a radius of $40 \mathrm{~km}$ from that grid cell, a power demand is found equal to the critical value of $50 \mathrm{MW}$. The distance to the load centres is used to estimate the additional transmission costs of wind and solar PV electricity. The results show that short transmission distances below $100 \mathrm{~km}$ prevail. Nevertheless there will be additional costs (Fig. 4). Typical costs for the construction of a $400 \mathrm{kV}$ overhead line are in the range of $100 \times 10^{3}-160 \times 10^{3} \$ \mathrm{~km}^{-1}[23,24]$, or 0.05 to 0.3 eurocent $\mathrm{kWh}^{-1} 100 \mathrm{~km}^{-1}$, from 100 to $4000 \mathrm{MW}$ transported [25]. They can vary considerably depending

\footnotetext{
(footnote continued)

conversion efficiency was assumed to be $10 \%$ and the total specific investment cost at $7 \$ \mathrm{Wp}^{-1}$. In the two regions annual average solar irradiance ranges between 60 and $250 \mathrm{~W} \mathrm{~m}^{-2}$ see [1].

${ }^{6} \mathrm{With}$ this amount of electricity produced, a small to medium sized city can be supplied.
} 


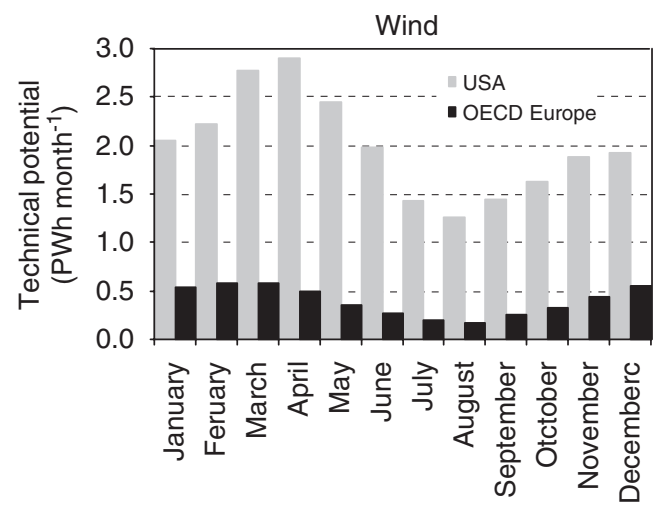

hours

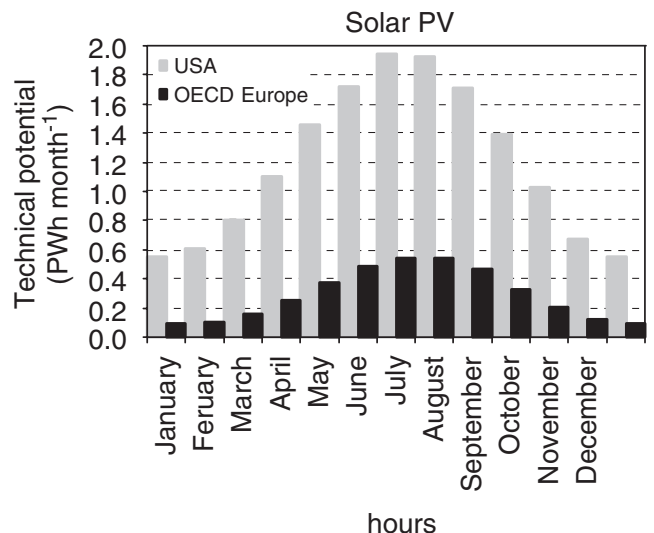

hours

Fig. 1. Monthly variation in an average year of the technical potential of wind and solar PV electricity at costs below $2 \$ \mathrm{kWh}^{-1}$, for USA and OECD Europe as constructed from Refs. [1,2] and used in the simulation experiments.

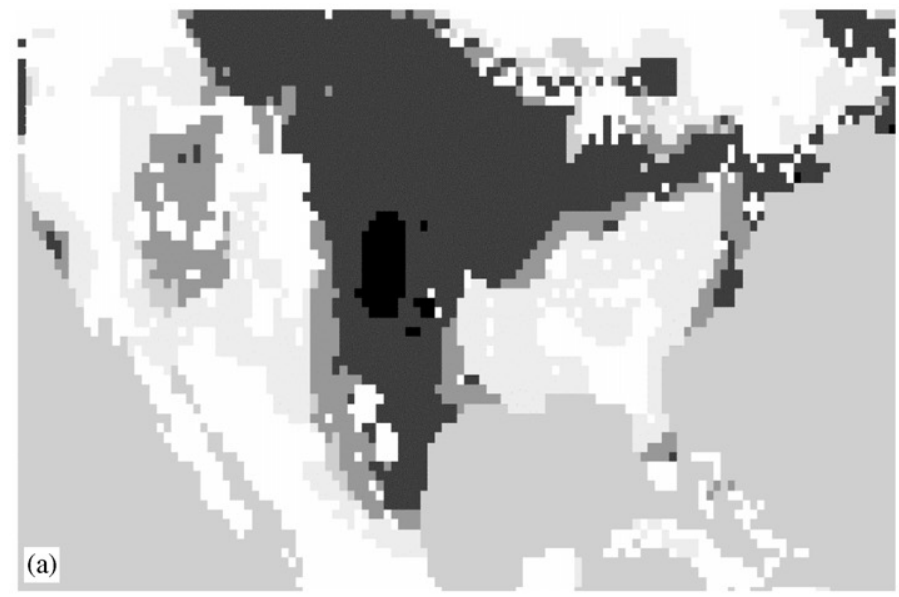

Exduded areas
costs acove $0.25 \$ / \mathrm{kWh}$
costs below $0.25 \$ / \mathrm{kWh}$
costs below $0.15 \$ / \mathrm{kWh}$

Costs below $0.06 \mathrm{~s} / \mathrm{kNh}$
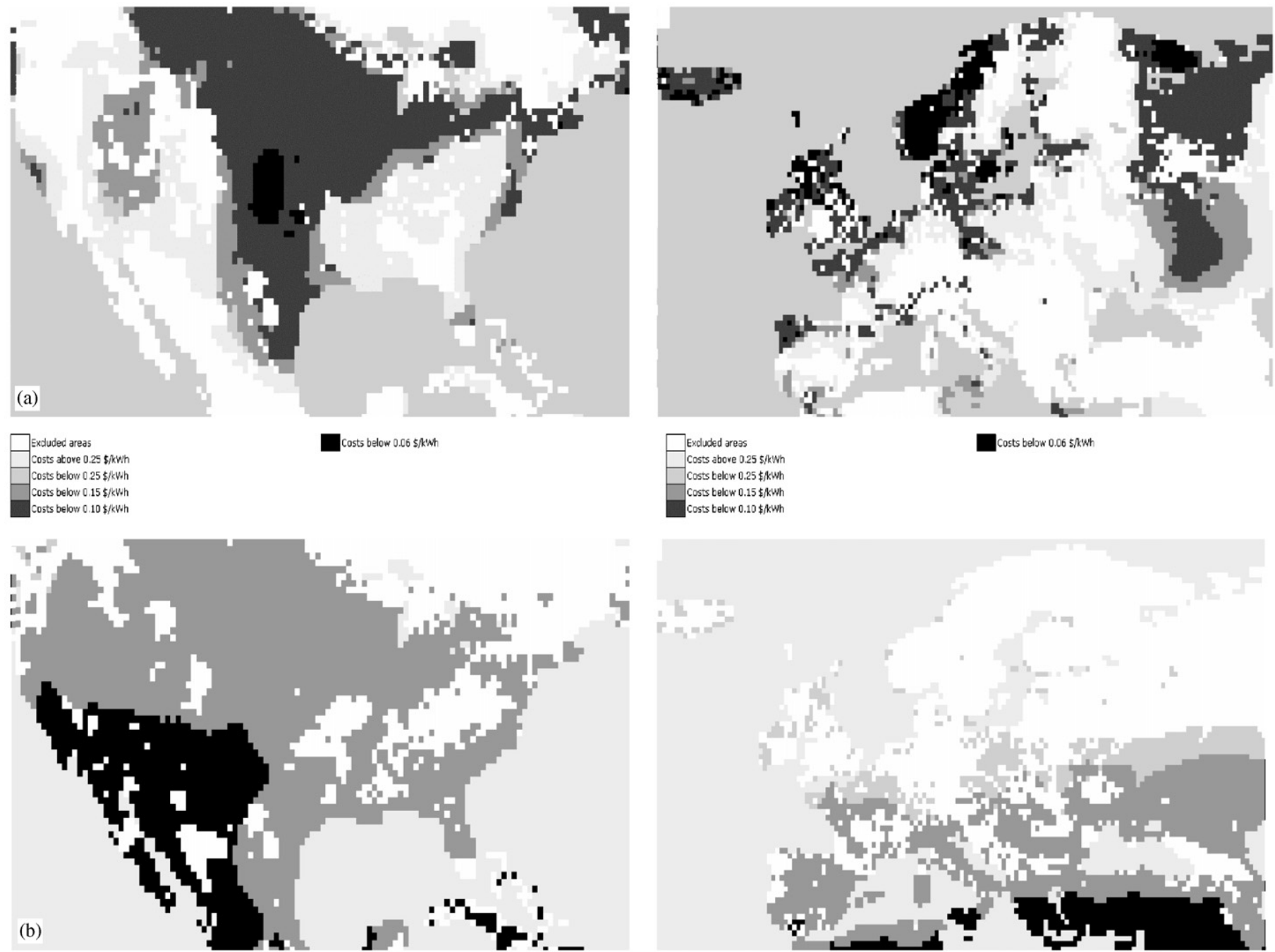

Costs below 0.06 5/kWh
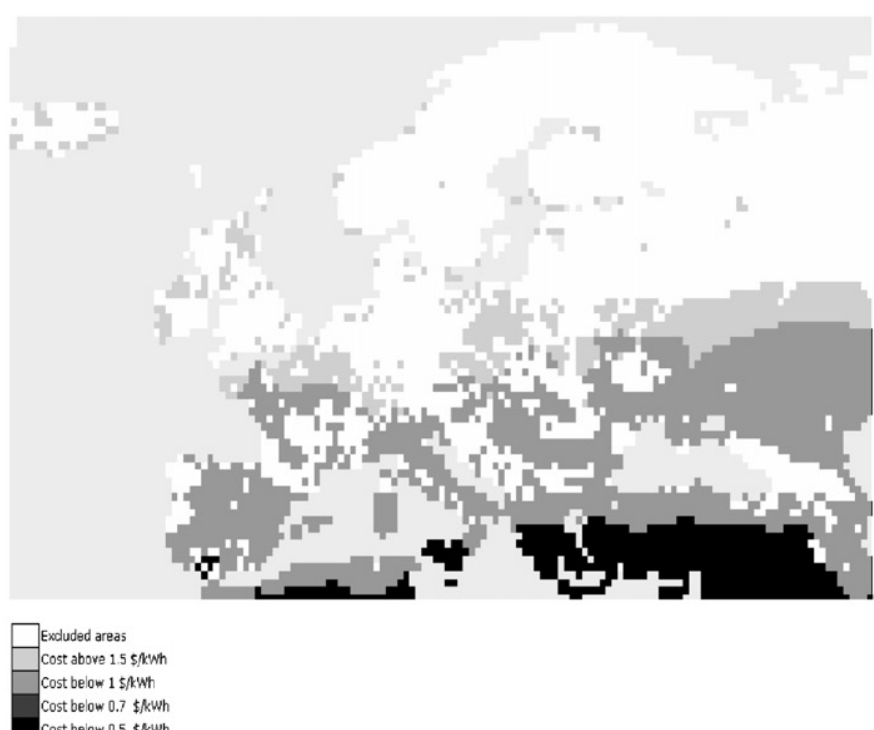

Cost be ow $0.7 \$$. $k$ Wh

Fig. 2. (a) Spatial distribution of wind turbine electricity costs (on-site), source: [2]. (b) Spatial distribution of module electricity production costs of solar PV (on site), source: [1]. 
Wind electricity

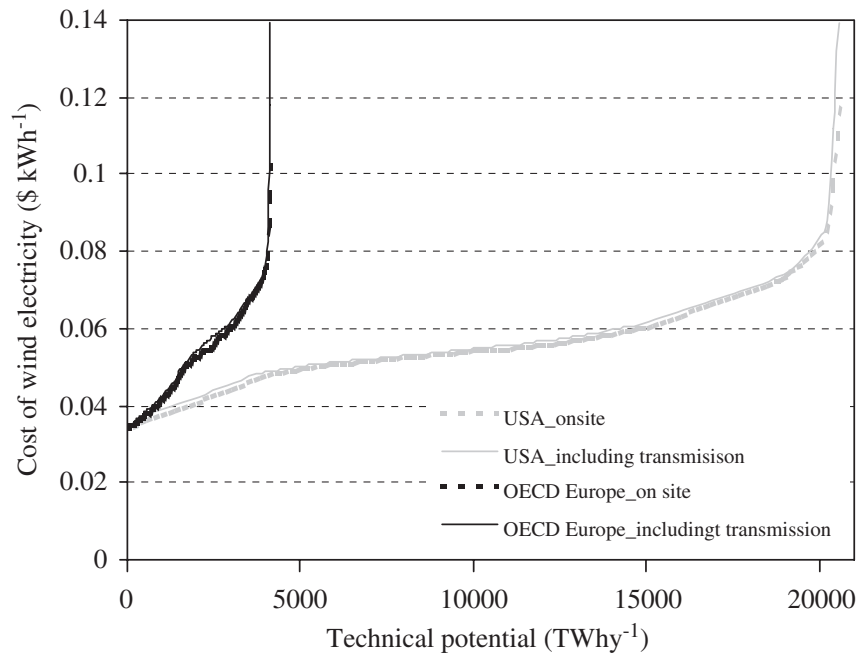

Solar PV

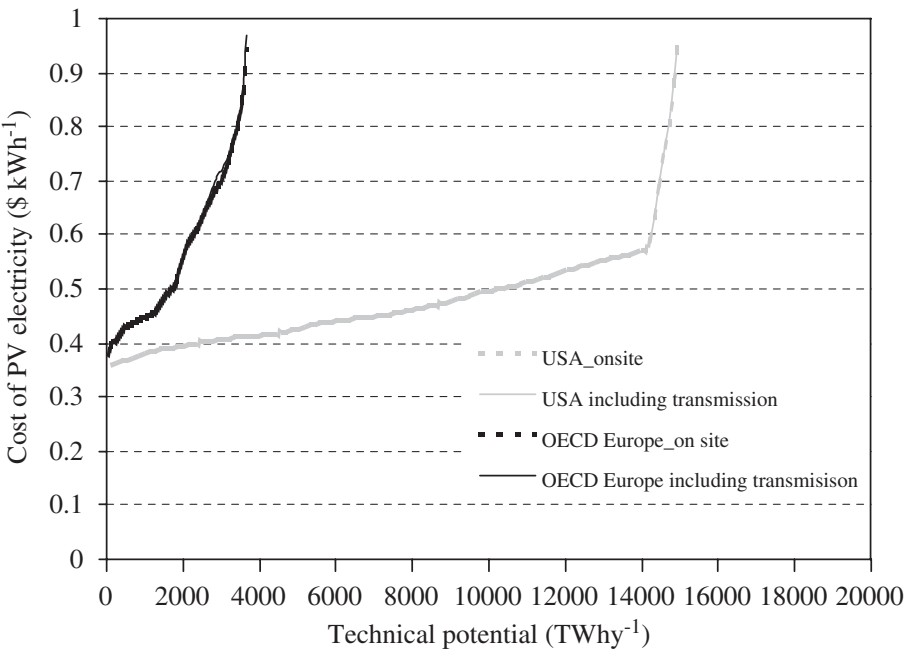

Fig. 3. The cost supply curve of wind and solar PV electricity in the year 2000 for USA and OECD Europe with and without inclusion of transmission costs.
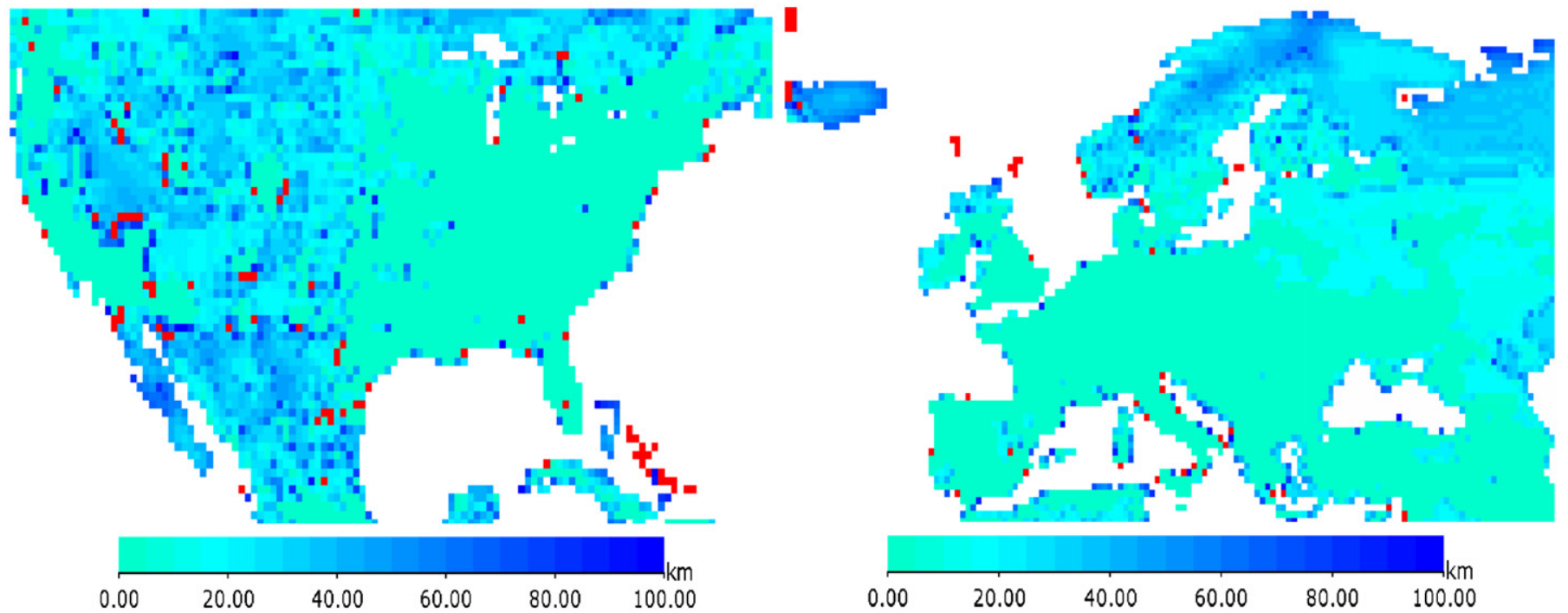

Fig. 4. Spatial distribution of the estimated transmission distances at grid cell level in USA and OECD Europe. A distance of e.g., $40 \mathrm{~km}$ means that within a radius of $40 \mathrm{~km}$ from that grid cell, an average power demand is found equal to $50 \mathrm{MW}$.

on specific circumstances like river crossing and mountains. In our cost calculations we assume investment costs of $160 \times 10^{3} \mathrm{Skm}^{-1}$, energy losses at $0.05 \% \mathrm{~km}^{-1}$, a lifetime of transmission lines of 60 years [26] and an interest rate of $10 \%$. These assumptions add up to about 0.2 eurocent $\mathrm{kWh}^{-1} 100 \mathrm{~km}^{-1}$, which would be the costs for the transmission of $250 \mathrm{MW}$ [25]. Note that in our study we include additional transmission costs only and neglect transmission reinforcements. The cost of the latter may be relatively small [14].

The sum of the production and transmission cost is rearranged in ascending order of costs; the resulting curves are also shown in Fig. 3. These costs do not include overheads like insurance and administrative costs, distribution and grid connection costs nor costs due to forced outages. ${ }^{7}$ It is seen that the resulting curve differs marginally from the curve without transmission costs for the two regions considered. This would be different if wind and solar PV electricity had to be transmitted at large distances as with resources in Patagonia, Mongolia and the Sahara [23].

\section{Factors determining the overall production cost of wind and solar PV in the electricity system}

Using intermittent sources such as wind and solar energy to produce electricity differs from generating electricity by

\footnotetext{
${ }^{7}$ Costs for forced outages have been included in [1,2], but are excluded in this Fig. 3 as the EPG model includes these costs afterwards.
} 
conventional power plants. Availability and quality are largely outside control of the system operator, which has technical and economic consequences for the power system at time scales varying from seconds and minutes to days and longer [27,28]. The focus of this study is mainly on the time-scale of days and longer, approximating more short-term aspects in aggregated system parameters (see Section 4).

The main objective of a power system is to satisfy the demand for electricity power efficiently and reliably within certain technical, environmental and economic constraints. This requires day-to-day operation of installed generation capacity in a way that follows the fluctuating demand at the lowest overall costs, within technical and environmental constraints. The basic rule-of-thumb here is the merit order strategy: power plants are operated in order of variable costs. Capital-intensive plants with low operational costs, such as nuclear but also wind and solar power plants, will therefore in principle be operated as many hours as possible, i.e. in the base-load. They may be run the whole year except when taken out for repair and maintenance or due to failure (forced outage). Consequently, they are filling the bottom part of the load duration curve (LDC) of a power system. Intermediate plants are designed to serve the shoulder load, which represents the fluctuations during most of the day. These intermediate plants are usually conventional plants in part-load operation that use a variety of fuels such as coal, oil or natural gas. Sometimes, the demand for power exceeds this base-load and shoulder-load and the system operator has to run plants with excellent load-following capabilities (generation that can ramp at a relatively high rate MW $\min ^{-1}$ ). During these periods and in particular in periods of extremely high demand (peak-load), units with low specific capital costs, quick-start capability and high variable costs due to their low conversion efficiency and/or expensive fuel, e.g., gas turbines or diesel engines are used. Also hydropower or pumped storage plants can be used during these periods.

\subsection{Additional cost factors with increasing penetration levels}

Various studies discuss the cost and value of wind and solar PV in the electricity system e.g., [11-14,29]. Based on these studies, we distinguish four mutually related factors which tend to cause additional costs as wind and solar PV power penetrate deeper into the local or regional system:

- Declining quality of the resource in terms of power density and location, i.e. depletion of the wind resources.

- The need for large investments in back-up capacity due to a low and decreasing "guaranteed capacity" or capacity credit of wind and solar PV power.

- Additional operational requirements, such as an increase of spinning reserve due to the fluctuating nature of wind and solar PV power.
- The necessity to discard part of the available wind and solar electricity at higher penetrations unless this energy can be stored.

\subsubsection{Declining quality of resource}

With increasing installed capacity, on site wind turbine or solar PV module power generation costs will tend to increase as less favourable sites with lower wind speed or lower irradiance, lower load factors and/or higher additional transmission costs come into operation. This depletion effect' is covered by the cost-supply curve (Fig. 3).

\subsubsection{Need for back-up capacity}

To ensure system reliability, ${ }^{8}$ the system operator has to reckon with the non-availability of wind-solar power during parts of the day and possibly during hours of maximum demand. As a consequence, for each additional MW of wind-solar capacity that is installed, only a small part can be considered to be available capacity from a system operating point-of-view. The fraction of the installed wind or solar PV capacity by which the conventional capacity of the electricity system can be reduced without affecting the reliability of the total system is called capacity credit (see e.g., [12,13,29]). Several utilities are reluctant to assign any capacity credit to wind power plants [30,31]. Present experiences and detailed studies on the capacity credit suggest that this is too pessimistic [11]. The capacity credit depends in the first place on the time characteristics of the source (wind/solar), secondly on the characteristics of the renewable energy conversion technology, thirdly on the penetration rate, fourthly on the characteristics of the other power plants in the system and finally on the grid characteristics.

The consequence of a low or zero capacity credit is that the reserve margin, defined as the ratio between the capacity of plants that should have been installed to guarantee a reliable electricity supply and simultaneous maximum demand (SMD), i.e. the highest maximum demand at a point in time, has to be increased by the installation of back-up capacity with good load-following capability [14]. Model experiments on the capacity credit of wind turbines show that at low penetrations the capacity credit is about equal to the load factor. For a system with up to $5-10 \%$ of its installed capacity in the form of wind turbines, most utilities accept $20-30 \%$ of the installed wind capacity as guaranteed. The remainder shows up in the form of cost-increasing back-up power that has to be installed additionally $[11,13,27,30]$. Part of these costs should be allocated to wind electricity production.

\subsubsection{Additional operation requirements}

The fluctuating nature of the wind-solar power generation requires significant load-following capabilities of the

\footnotetext{
${ }^{8} \mathrm{~A}$ widely used measure of reliability is the loss of load probability (LOLP), that is the probability that a certain load can(not) be met in the given system, e.g., a criteria of 1 day per 10 years.
} 
system. For instance, additional spinning reserve and possibly a change in operational strategy (more loadfollowing operational capacity) have to account for the possibility of short-term drops of significant amounts of intermittent power e.g., due to storms in which the wind speed exceeds the cut-out wind speed of the turbine. Such quick-start capacity is normally obtained by the so-called spinning reserve, that is, conventional thermal capacity operated at less than its full rating [14]. With high penetration of intermittent sources, it needs to be higher and leads to more fuel use and emissions. A typical level of spinning reserve at system level is $1.5-3 \%$ of the peak load [27], depending amongst others on the size of the largest plant. Estimates of the spinning reserve required at high wind power penetration given in the literature range from about $10 \%$ to $85 \%$ of the installed wind capacity $[12,14,30]$. As shown by Grubb [12], the highest end of the range is unlikely high and is only to be expected if the existing park relies on large amounts of slow-start capacity, e.g., large nuclear or coal-fired plants and/or if no good forecasting instruments are available. Fellows [14] assumes in his assessment on the cost of wind electricity no additional need for spinning reserve thanks to the use of wind forecasting, wind curtailment and additional peaking capacity.

Another reason for increasing costs with rising shares of wind and solar PV power are additional operational losses. Parts of the conventional power plants in generation will make more repeated plant starts or be operated more often on part load - both causing additional fuel costs and emissions. According to Grubb [12], such operational losses might be in the range of maximum $5-8 \%$ of the fuel use in the operated plants. We have not included this effect in our study as we do not simulate each plant separately [12].

\subsubsection{Discarded electricity}

A related cost impact with increasing penetration of intermittent sources is that part of the power may be generated at times when the system cannot use it, due to the demand profile, the strategy of power supply used in the system or limited transmission capability. Without storage options (mechanical or chemical) this electricity is to be discarded. For the European situation the amount of discarded wind power has been studied by Giebel [11]. He found that at wind power penetration (on electricity basis) of about $35 \%$ in the European electricity system, on average up to $25 \%-35 \%$ may remain unused, depending on the accuracy of the forecasting system for wind power [11]. Much lower levels of discarded wind electricity are mentioned for the Egyptian and UK situation by Fellows [14]. He assumed the global average wind to be discarded as function of the penetration of total annual electricity consumption to be zero at levels up to $25 \%$, rising to $60 \%$ at $100 \%$ of wind electricity produced as percentage of total electricity production. Evidently, new systems to store electricity or to convert it to a chemical carrier such as hydrogen in combination with fuel cells, can significantly alter these estimations.

\subsection{Related aspects for the overall cost development of intermittent electricity}

At least four related aspects determine how much the above factors will influence the penetration and costs of intermittent sources: their geographical dispersion, the ability of power forecasting, the load following capabilities of the generation mix and the interconnection with other grids.

\subsubsection{Load supply curve of intermittent sources: geographical dispersion}

If wind or solar power supply is geographically uncorrelated, fluctuations in both supply and in severity and frequency are reduced and supply is smoothened. For the Northern European countries it was found that wind power supplies from sites of more than $1500 \mathrm{~km}$ apart are nearly uncorrelated [32]. For the Nordic countries it was found that on a time scale of $12 \mathrm{~h}$, variation can be up to $30 \%$ once a year and production is never completely down. If data of only Denmark are used, production can come down to zero in about a few hours. Similar results for wind supply are found for Germany: fluctuations for a single turbine on a time scale of 12-h were reported over the total power range $(100 \%)$, whereas the output of 1496 widely spread turbines showed maximum variations of $60 \%$ in the 4-h gradient [33]. This effect of geographical dispersion reduces within a well-connected system the need for backup and spinning reserve capacity due to a smoothening of output fluctuations and will also reduce the amount of discarded electricity.

\subsubsection{Forecasting of power output}

The planning of slow-start and quick-start capacity operation is typically done a day ahead. If the load expected from intermittent wind and/or solar PV power can rather accurately be forecasted within this period, it improves the utilisation of these sources and lowers operational costs [34]. In the USA and Europe commercial wind forecasting instruments are available and applied [30]. Typical accuracy reached for forecasting wind power $48 \mathrm{~h}$ ahead are in the order of $10 \%$, but also less accurate forecasts are mentioned [34,35].

\subsubsection{The load following capacity of the generation mix}

The load following capability of the generation mix is an important factor. Large numbers of quick-start plants such as gas turbines and/or hydropower or storage plants with high load-following capability can absorb larger amounts of intermittent supply than typical base-load units such as large nuclear and coal-fired plants [11,27]. If large fluctuations occur, this cannot be dealt with using baseload plants. If the load following capacity is limited, it implies 
that wind power will be discarded at any significant degree of penetration [12].

\subsubsection{Interconnection with other grids}

Interconnection between electric power systems increases the capability to match supply and demand. The importance of interconnection of national systems in Europe can be illustrated by two extreme cases: Denmark and Spain. The interconnection of the Danish system with the Nordic and the German system is about $30 \%$, in contrast to about $3 \%$ interconnection of Spain with France. The main reason for the smooth penetration of large quantities of wind in the Danish system is the well-established interconnection with the Nordic countries having large quantities of hydropower [33]. The fact that the Red Eléctrica Española (REE) in Spain can import very little power to cover drops in voltage is mentioned as one of the main reasons for the grid instabilities due to wind power in Spain, next to the low geographical dispersion of the wind resources and the difficulties with wind forecasting in mountainous areas [36]. The degree of interconnection affects the capacity credit as well as the amount of discarded wind electricity.

\subsection{Technological learning: declining capital costs}

There is one major factor that may cause a decline in production cost with increasing penetration: technological learning that reduces the specific investment costs. Wind and solar PV technologies have developed significantly in the past decades. Wind turbines have increased in scale, from about $30 \mathrm{~kW}$ in the mid-1970s (rotor diameter about $10 \mathrm{~m}$ ) to above $1 \mathrm{MW}$ at present (rotor diameter about $80 \mathrm{~m}$ ). Due to this up-scaling and other developments such as more production, gear improvements etc, large reductions in wind electricity production costs took place. Technological developments of solar PV modules reduced module costs and increased conversion efficiencies. For the future, further reductions are expected in wind and solar PV electricity production cost. It is empirically observed that costs tend to evolve as a power function of the cumulative production, which can be plotted in a so-called experience curve (see e.g., [37,38]). For wind and solar PV various historical experience curves have been constructed (see [4,39-43]); This historical evidence suggests that with further penetration, the specific (capital) cost of these technologies can come down. This effect should be included when studying the cost of intermittent electricity with increasing penetration.

\section{Simulation of wind/solar PV penetration: the use of the TIMER-EPG model}

The penetration of wind and solar PV in the North American and European electricity systems is simulated using the electricity sub-model of the TIMER 2.0 model [16]. It is an intermediate-level model based on the use of a Load Duration Curve that focuses on the overall long-term dynamics of electricity production, within 17 world regions.

\subsection{General description of TIMER-EPG}

The EPG model simulates investments in various technologies of electricity production in response to electricity demand, based on changes in the relative fuel prices and changes in relative generation costs of thermal and non-thermal power plants. It contains simple rules for operational strategies at monthly level and results in costs and emissions of power production. For a detailed description of the EPG module we refer to [16]. The EPG model and its use in this study are represented in Fig. 5, with a focus on the use of intermittent sources. In our experiments, demand for capacity is solely based on the need for replacement capacity, as we use constant regional electricity demand and load curve in our model experiment. The investment strategy is based on operational costs, resulting in market shares of technologies that are loaded in the operational strategy. The costs of intermittent sources are determined by the cost-supply curves (Fig. 3), by technology-induced cost reductions and by additional costs from discarded electricity, back-up capacity and additional required spinning reserve (see Section 3).

\subsection{Technologies included}

The TIMER-EPG model includes 25 different technologies of which a number are used in this study (see Table 2). The installed capacity for the year 2000 in the USA and OECD Europe is derived from model simulations for 1971-2000 and calibrated with statistical data [44,45]. For each technology used in this study the installed capacity in the year 2000 and 2050 (for Experiment A-Section 1), the specific investment costs and technical lifetime and the fuel costs of coal, oil, gas and biomass are given in Table 2. The data for the year 2000 in Table 2 are the results of the simulations for 1971-2000.

\subsection{Investment strategy}

In the regular version of the TIMER-EPG model, the demand for capacity is determined by expansion capacity due to an increase in electricity demand, replacement capacity due to depreciation of existing capacity at the end of its technical lifetime ${ }^{9}$ and a demand for additional capacity (e.g., back-up capacity) given certain reliability constraints. In our experiment the demand for capacity and the investment strategy are constrained in the model experiments as follows:

\footnotetext{
${ }^{9}$ If the capacity has a technical lifetime of 25 years (see Table 2), after 20 years a fraction $(10 \%)$ of the installed capacity is replaced each year until 5 years after the technical lifetime. This accounts for the fact that some plants have a longer and other plants a shorter technical lifetime than average.
} 


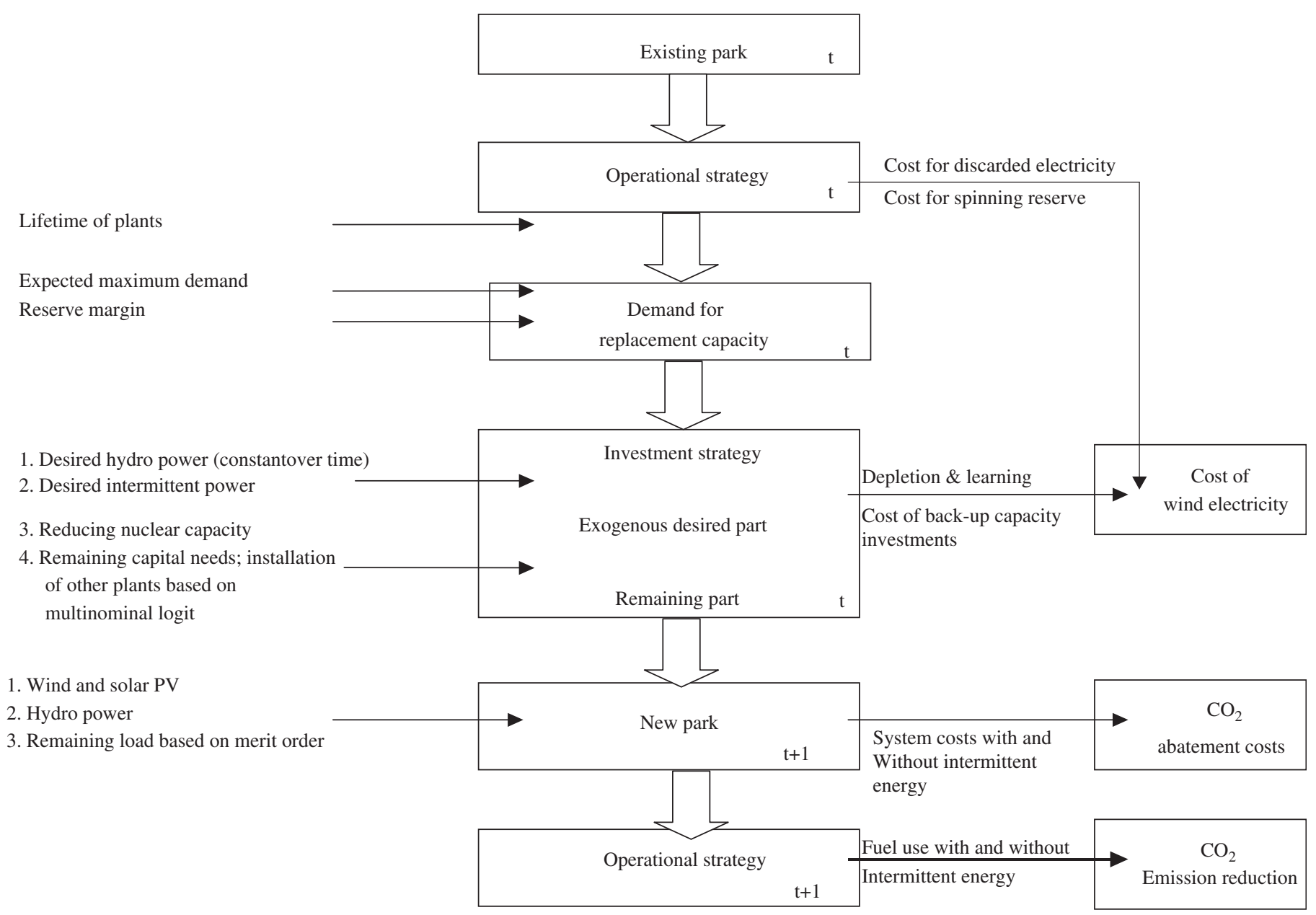

Fig. 5. Schematic presentation of the annual use of the TIMER-EPG 2.0 model indicating the simulated steps from year $t$ to year $t+1$.

- We assume the electricity demand to remain constant from 2000 onwards; only demand for replacement capacity is installed. This is done as we rather have a more controlled experiment that focuses on the effects of the penetration of intermittent sources, without intervention of other dynamic effects like cost reductions and increase in fossil fuels prices, competition between back up capacity with other conventional plants, etc.

- We force the construction of intermittent source capacity using two penetration paths (see Section 1), with a maximum of the replacement capacity. Reliability is maintained by assuming the installation of additional capacity in accordance wit the capacity credit.

- Hydro capacity investments are made such that the capacity is constant over time; nuclear capacity is not replaced and therefore declines over time because of depreciation (see Table 2).

- For the remaining demand for capacity, i.e. the demand for replacement capacity minus the desired capacity for intermittent (plus back-up capacity) and hydro replacement, market shares are calculated from the relative generation costs in a multinomial logit formulation. This formulation assigns a market share to all options based on relative generation costs; for a detailed description see [15].

\subsection{Electricity demand}

Gross electricity demand is taken from the energy demand module of the TIMER 2.0 model for the period 1971-2000, for calibration purposes and assumed to be constant thereafter. It is equal to the sum of the annual net electricity demand, net trade and net transmission losses. The average monthly demand is constructed from this annual demand with an exogenously derived annual load demand curve $(\mathrm{LDC})^{10}$ for both regions. The load distribution within a month is based on two parameters that indicate the minimum and the maximum demand (Fig. 6). The LDC and these parameters are derived from a module that includes the monthly distribution of mean temperature and daylight hours, and are kept constant in

\footnotetext{
${ }^{10}$ When classifying this monthly demand in 10 equal fractions, an approximation of the load duration curve can be given.
} 


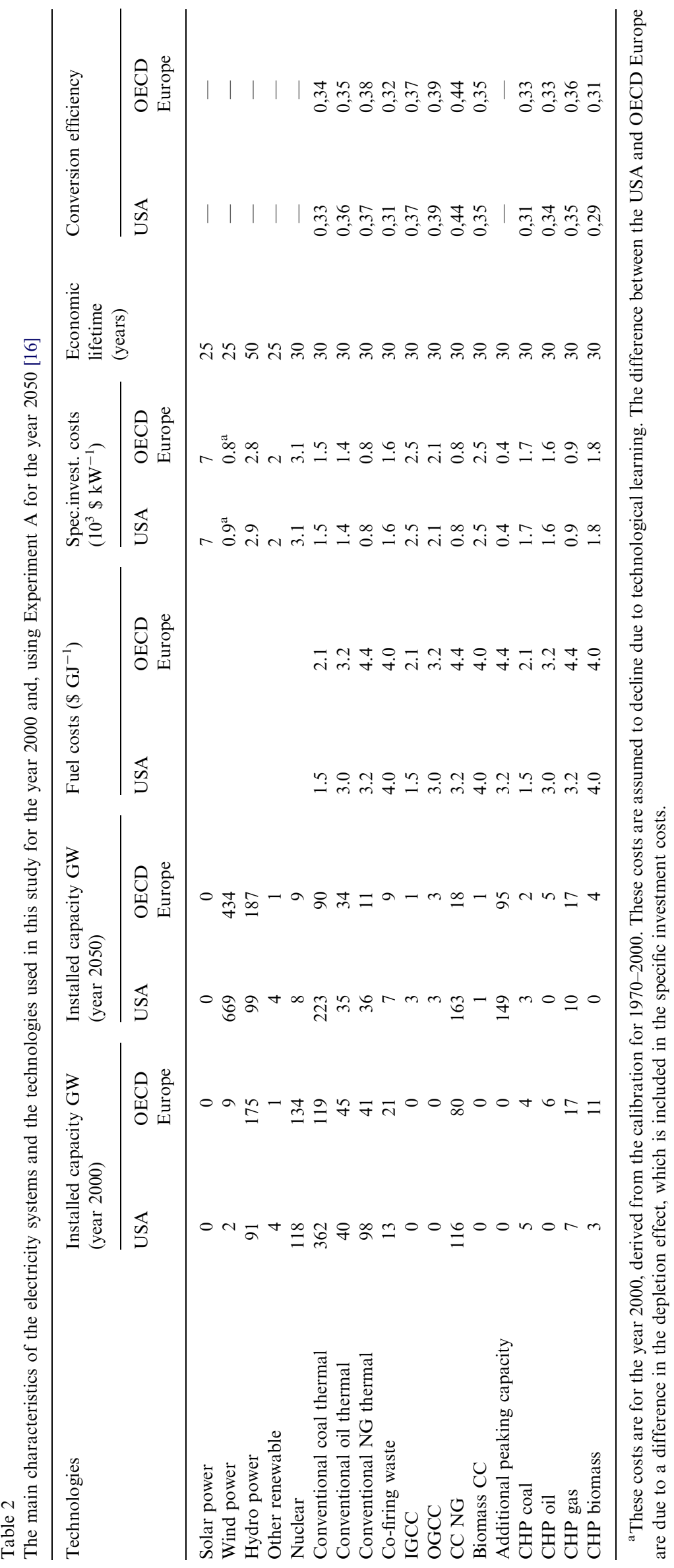



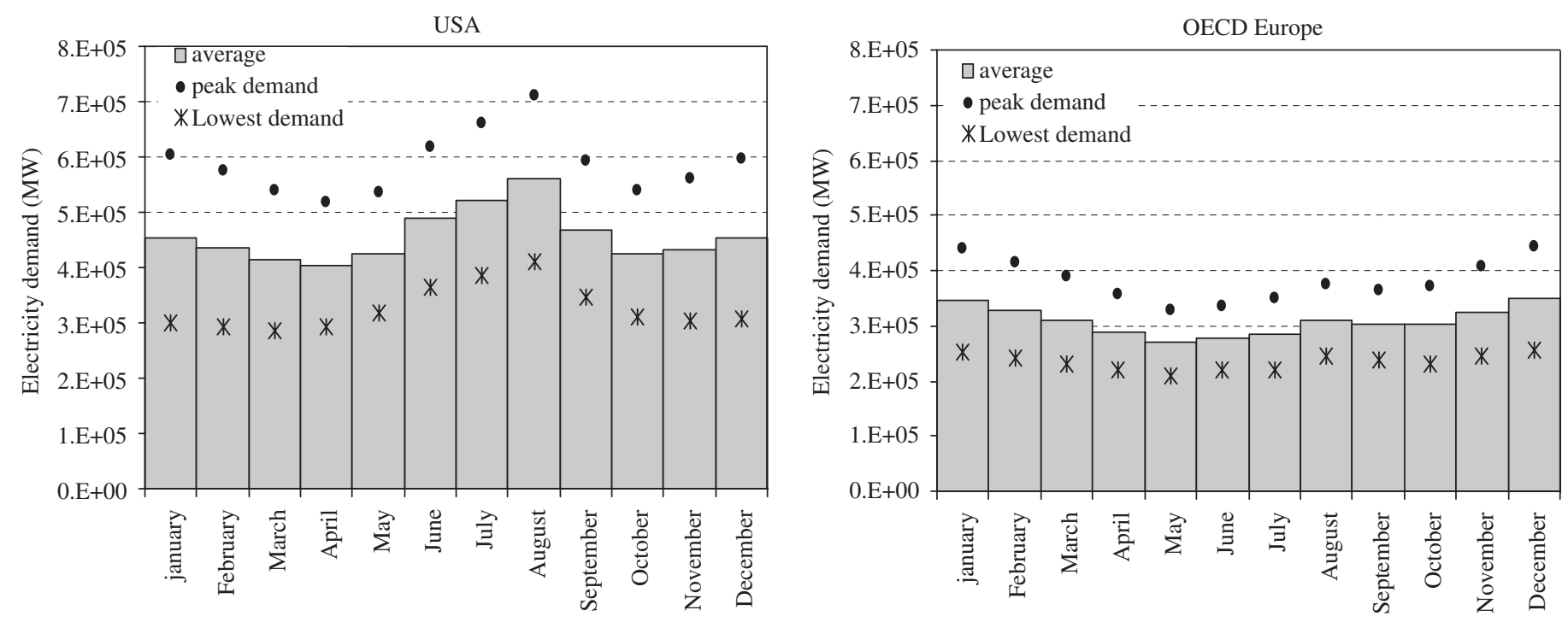

Fig. 6. The estimated monthly distribution in the simulated load demand for USA and OECD Europe in the year 2000.

the future [16]. The estimated net electricity demand for the USA and OECD Europe in the year 2000 and the upper and lower limit of demand in the twelve months are shown in Fig. 6. The demand for capacity is derived from the maximum demand and a fixed reserve margin of about $10 \%$ of the ratio of the desired installed capacity multiplied with the load factor and the maximum demand. This margin is based on a comparison of the SMD in Europe with the European installed capacity. The SMD is estimated as the sum of the load duration curves in seven European countries, covering about two third of the European demand [16].

\subsection{Operational strategy}

The operational strategy determines how much of the installed capacity is used and when. It reflects that electric power companies have the objective of minimising the production costs while maintaining the required system reliability. The analysis we are conducting here is done at large time an geographical scale. In reality the operational strategy is done at second basis. We have to approximate this strategy and use a static approach based on the monthly LDC. The merit order strategy is the most costeffective strategy and assumed here. Thus, wind and solar PV capacity is loaded first in the simulation because of zero or low operational costs, followed by hydro capacity. Hydro capacity is dispatched after wind, as it is much more flexible compared to wind and solar PV, however is dispatched before conventional sources, because of the merit-order strategy. The distribution of solar PV and wind is explained in the following section and given in Fig. 7. In reality, the merit order strategy is more complex: with intermittent sources conventional power should also be operated at part load. At higher penetration rates of intermittent sources, this effect is taken into account in the simulation by making $\varphi<1$ and is equivalent to an increase in the electricity discarded. The resulting monthly LDC is restructured, divided in one part peak load and one part baseload and the remaining generating options are planned according to the merit-order strategy, in which capacity is operated according to variable costs.

\subsection{Wind and solar PV electricity}

\subsubsection{Supply of wind and solar PV electricity}

To account for the variation of wind power within a month in order to estimate the amount of discarded electricity, we simulate the distribution of wind power as a combination of two extreme situations: (1) wind power supply coincides fully with the LDC, i.e. is fully correlated with the electric power demand at the level of the simulation (monthly in 10 equal parts) and (2) it fully anti-coincides (Fig. 7). The actual coincidence of wind supply and the LDC is assumed to be a combination of these two, based on figures about wind supply distribution in Scandinavia and the rest of Northern Europe [32]. Using the two extremes of wind supply to estimate the amount of discarded electricity is not equivalent to a random variation around the means, but the uncertainty related to the exact form of the load supply curve of wind power is considered larger than the error when using this approach.

For solar PV, a parabolic shape is used to describe the coincidence with the LDC, such that within a month, the solar PV supply never fully coincides with the peak demand and, during parts of the month at low load demand, the supply is down to zero. Within a region, this may not be a correct representation, e.g., for sunny areas in the USA solar PV supply is found to coincide with the peaking demand, mainly for cooling. It also neglects the time differences across regions stretching over many degrees longitude. However, for a region as a whole, this shape is 

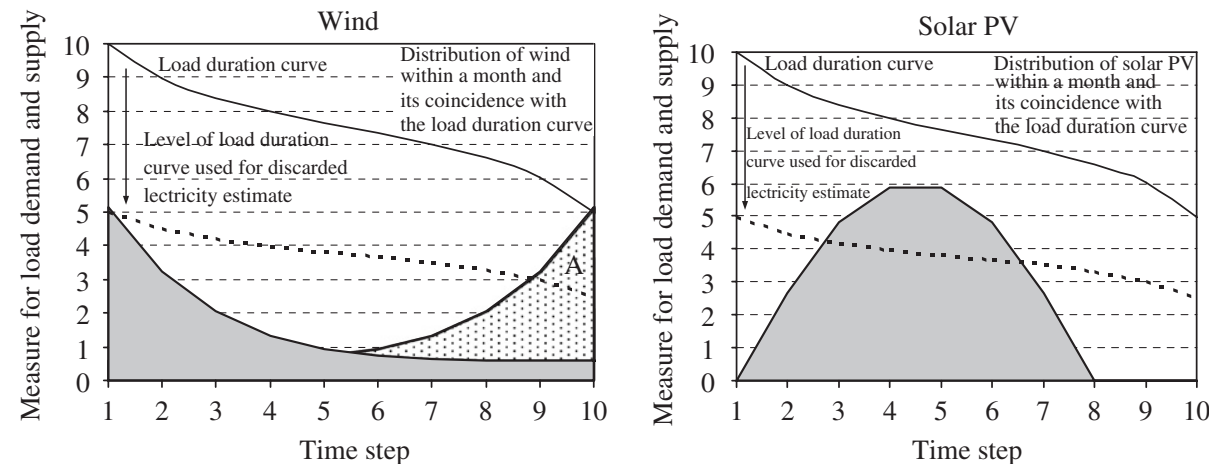

Fig. 7. Illustrative representation of the contribution of the wind and solar PV power supply within the 10 time steps of a month: their coincidence with the load duration curve and the method to calculate the amount of discarded wind and solar PV electricity.

preferred. Planned outage at a level of $5 \%$ of the installed wind and solar PV capacity is assumed to be allocated over the lowest demand months. Forced outage at a level of $5 \%$ of the installed capacity is allocated uniformly on the year.

\subsubsection{Discarded wind and solar PV electricity}

Wind and/or solar PV electricity is discarded if it exceeds the electricity demand in a month as given by the LDC. This mismatch between demand and supply is in the range of hours within a day and detailed studies are required to calculate the discarded electricity. At the level of aggregation we are simulating, we have to derive parameters from these detailed studies at hourly level. Given limited interconnection between the systems in which intermittent sources are installed and also operational constraints (see Section 4.8), electricity is probably discarded earlier than at the minimum load demand of the LDC. To account for that, we introduce the 'mismatch coefficient' $(\varphi)$. The LDC is multiplied by this factor $(0<\varphi<1)$ to obtain the level from which wind or solar PV power starts to be discarded. The discarded electricity for wind is $50 \%$ of the summed areas under curves $A$ and $B$ in Fig. 7, as it is assumed that this extreme situation occurs for $50 \%$ of the time. For solar $\mathrm{PV}$ it is the part of the parabola above the dashed line (C).

\subsection{Spinning reserve and back-up capacity}

The total amount of required spinning reserve is assumed to be $3.5 \%$ of the installed capacity of the conventional park. If wind and solar PV penetrate the market, it is assumed that more spinning reserve is needed equivalent to about $15 \%$ of the intermittent capacity. This additional spinning reserve will not be allocated until the overall spinning reserve capacity exceeds $2 \%$ of the conventional park. This reflects the assumption that part of the required spinning reserve can be covered by the existing spinning reserve in the system. The fuel cost for the additional spinning reserve is allocated to wind electricity.

Back-up capacity is added to account for the low capacity credit of the intermittent sources. It is calculated as the product of the rated installed wind power and one minus the capacity credit. For the first $5 \%$ penetration of the intermittent capacity, the capacity credit is made equal to the load factor of the wind turbines. After further penetration, the capacity credit is assumed to decrease linearly to a value of 0.1 at $50 \%$ penetration (at capacity basis). Thus at $50 \%$ penetration (at capacity basis), the back-up capacity is equivalent to $90 \%$ of the installed intermittent capacity. To install back-up capacity from the beginning may be conservative as some argue that up to $10 \%$ wind electricity penetration the existing park can account as back-up capacity [14]. Plants with the lowest capital costs are assumed to be installed and used as backup power which in our study is mainly gas combined cycle and conventional gas thermal plants. It is assumed that both gas combined cycle and peaking capacity is used for back-up in the ratio $1: 2$.

$30-50 \%$ of the cost for the back-up capacity is allocated to the production costs of the intermittent sources, because the installed back-up capacity can also be used in the operational strategy. We assume that for the first $5 \%$ wind penetration (at capacity basis), $30 \%$ of the capital costs of back-up plants are allocated to the wind turbines generation costs. This increases to $50 \%$ if wind capacity reaches $50 \%$ penetration level (on capacity basis). The discounted capital costs of the back-up capacity, using same interest, but specific lifetime) are added to the discounted turbine costs used for the calculation of the wind electricity costs.

\subsection{Technological learning: declining capital costs}

Technological learning is introduced in the form of an experience curve at a global level, leading to specific investment cost reductions. For wind power we follow the more conservative figure published by [39] and use a progress ratio $(\mathrm{PR})^{11}$ of 0.9 between the year 2000 and 2050. This rate of cost decrease is slower than the estimated historical global rate for wind turbines, with an estimated $\mathrm{PR}=0.81-0.85$ [41]. Also, it should be mentioned that

\footnotetext{
${ }^{11}$ The progress ratio is a measure for the specific investment cost reduction with each doubling of the production of a technology X. A PR of 0.9 means that the cost of technology $\mathrm{X}$ decreases $10 \%$ for each doubling of the production.
} 
Table 3

The amount of capacity installed, electricity produced and electricity absorbed in the electricity system in the USA and OECD Europe if wind or solar PV capacity penetrated to about $50 \%$ (on capacity basis) for two penetration paths (Section 1 )

\begin{tabular}{|c|c|c|c|c|c|}
\hline & \multirow[t]{2}{*}{ Unit } & \multicolumn{2}{|l|}{ USA } & \multicolumn{2}{|c|}{ OECD Europe } \\
\hline & & Wind & Solar PV & Wind & Solar PV \\
\hline \multicolumn{6}{|l|}{ Experiment $A$ (2050) } \\
\hline Capacity installed & GW & 669 & 678 & 434 & 515 \\
\hline Capacity installed as percentage of total installed capacity & $\%$ & 47 & 47 & 47 & 47 \\
\hline Electricity potentially produced & TWh yr ${ }^{-1}$ & 1910 & 1095 & 1252 & 830 \\
\hline Electricity potentially produced as percentage of techn. potential & $\%$ & 9 & 7 & 30 & 23 \\
\hline Electricity absorbed in the electricity system & TWh yr $^{-1}$ & 1475 & 881 & 990 & 567 \\
\hline Electricity absorbed as percentage of electricity consumed & $\%$ & 40 & 24 & 43 & 24 \\
\hline Electricity discarded as percentage of intermit. elect. produced & $\%$ & 23 & 20 & 21 & 32 \\
\hline \multicolumn{6}{|l|}{ Experiment B (2050) } \\
\hline Capacity installed & GW & 595 & & 434 & \\
\hline Capacity installed as percentage of total installed capacity & $\%$ & 44 & & 47 & \\
\hline Electricity potentially produced & TWh yr ${ }^{-1}$ & 1714 & & 1251 & \\
\hline Electricity potentially produced as percentage of techn. potential & $\%$ & 8 & & 31 & \\
\hline Electricity absorbed in the electricity system & $\mathrm{TWh}^{-1}$ & 1406 & & 990 & \\
\hline Electricity absorbed as percentage of electricity consumed & $\%$ & 38 & & 43 & \\
\hline Electricity discarded as percentage of intermit. Elect. produced & $\%$ & 18 & & 21 & \\
\hline
\end{tabular}

experience gained in other regions is not considered in our constrained experiment.

\subsection{Additional overhead costs}

We have corrected the electricity production costs for grid connection and overhead costs (insurance, administration costs, distribution costs, etc.). ${ }^{12}$ For wind electricity we used a recent estimation of the delivered cost of wind electricity in the Netherlands [46] and multiplied the cost values of the supply curves in Fig. 3 with the ratio between the estimates and the cost values. This ratio is 1.5 and results in a higher cost-supply curve with a lowest value of the production costs in the year 2000 of about $8 \notin \mathrm{kWh}^{-1}$ for wind electricity. Similar factors are also used in TIMER-EPG for other technologies.

\section{Results}

We can now address the questions related to high penetration of wind and/or solar PV in the electricity system as formulated in the introduction. The methodology has been explained for both wind power and solar PV. Our main focus for the results is on wind as more detailed studies are available for wind power. Such studies are required to estimate the mismatch factor. We present results of solar PV only for comparison, using the same mismatch factor.

\footnotetext{
${ }^{12} \mathrm{As}$ we focus our cost analysis on wind, this correction has only been applied for wind electricity.
}

\subsection{Intermittent electricity production and load factor (Experiment A)}

In Experiment A (Section 1) we analyse the amount of wind and solar PV capacity installed, and electricity produced and absorbed in the system if wind and solar PV independently penetrate linearly to a desired level of $50 \%$ penetration (at capacity basis) in 2050 . The system features are given in Table 3.

Fig. 8 shows the marginal ${ }^{13}$ load factor ${ }^{14}$ of wind and of solar PV capacity in the two regions as function of their penetration ${ }^{15}$ (expressed as annual electricity produced as percentage of total electricity produced). It declines from 0.37 to 0.32 (USA) and 0.29 (OECD Europe) at about 40 (USA) - 43\% (OECD Europe) annual electricity production as percentage of total annual electricity production. Average values, based on absorbed electricity, are in the order of 0.35 at about $43 \%$ electricity produced as percentage fo total electricity produced. This is rather high compared to average load factors for wind turbines reached in OECD Europe in 2000, ranging from 0.21 in Germany to 0.32 in the UK [47]. However, for single projects, higher load factors are not uncommon, even of 0.51 in New Zealand [48] and 0.41 in the US [49]. One explanation is that our figures are based on a turbine size of $1 \mathrm{MW}$ whereas the average turbine size installed in OECD

\footnotetext{
${ }^{13} \mathrm{We}$ use in this study both marginal and average value. The latter is referring to the average over the total installed capacity. The former refers to the value for the latest installed unit.

${ }^{14}$ The load factor (for wind and solar PV) is the ratio of the full-load hours per year and the total amount of hours in a year.

${ }^{15} \mathrm{We}$ use penetration level on electricity basis, as this is most comparable with figures from the literature. Intermittent electricity penetration level is defined as ratio of the absorbed intermittent electricity and the total produced electricity.
} 

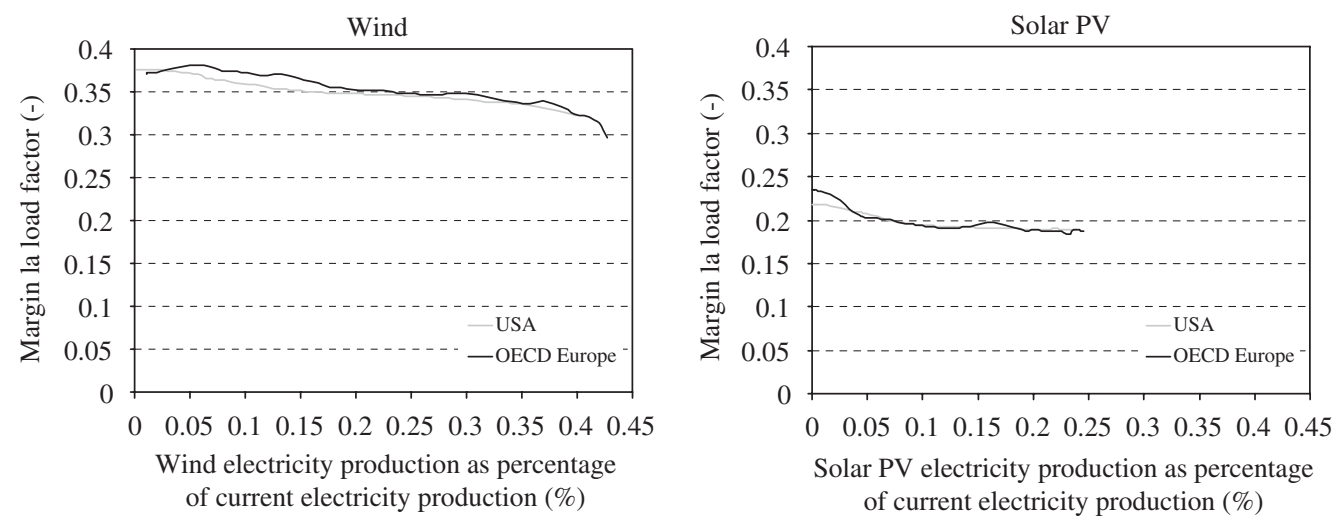

Fig. 8. Marginal load factor with increasing electricity penetration of wind and solar PV.

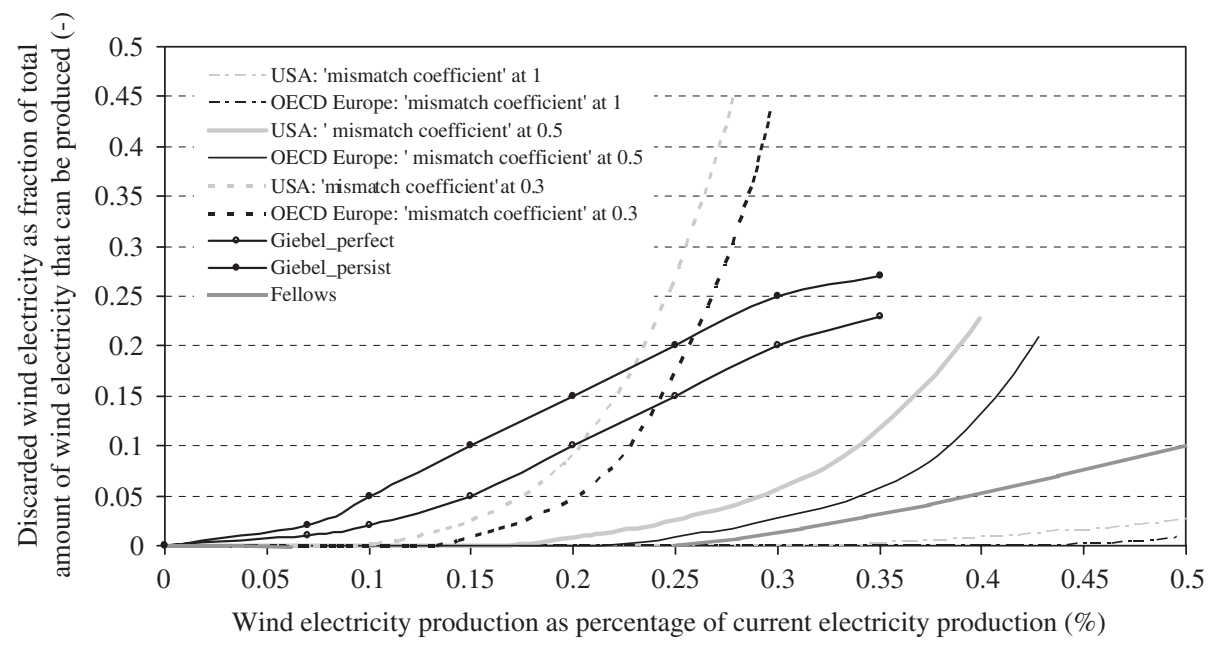

Fig. 9. Average value of discarded wind electricity in the USA and OECD Europe indicated as fraction of the potentially produced wind electricity, as function of the penetration (on electricity basis), within Experiment A and for three values of the 'mismatch coefficient' $\varphi$.

Europe in 2000 ranged from $484 \mathrm{~kW}$ in the UK to $646 \mathrm{~kW}$ in Germany [47]. A smaller turbine implies in practice lower hub heights, resulting in operation at lower average wind speed and probably load factor. Higher load factors can be explained as our wind speed values are gird-cell averages.

For comparison, we include the results of solar PV. Here the load factor is related to solar irradiance. Depending on the penetration rate, the marginal load factor drops from 0.22 to 0.19 in the USA and from 0.23 to 0.19 in OECD Europe.

\subsection{Discarded electricity from intermittent sources (Experiment A)}

In the case of wind electricity production, according to Experiment A (Section 1), Fig. 9 shows the amount of discarded wind electricity as function of penetration for three values of $\varphi(0.3 ; 0.5$ and 1 , see Section 4.7). The results suggest that at ideal conditions (i.e. $\varphi=1$ ), wind electricity is discarded from about $40 \%$ electricity penetration onwards. The discarded amount of electricity is about $1 \%$ (OECD Europe) - 3\% (USA) at about 50\% electricity produced as percentage of total system electricity produced. If we consider $\varphi=0.5$, wind electricity is discarded from about $18-19 \%$ electricity penetration onwards (meaning $18-19 \%$ annual wind electricity produced as percentage of total system electricity produced). If wind penetrates to about $40 \%$, about $21 \%$ (OECD Europe) and 23\% (USA) respectively of the wind electricity is estimated to remain unused. In this case the amounts of discarded electricity are higher than the figures assumed by Fellows [14], but slightly lower than estimated by Giebel [11]. Our results approach estimates of Giebel [11] for $\varphi=0.3$. Evidently, the choice of $\varphi$ is important but difficult as, on this stage, no empirical evidence is available yet for its value. We consider the values derived by Giebel rather low and prefer $\varphi=0.5$ delivering results in between Fellows [14] and Giebel [11] (Fig. 9). The discarded electricity represents the mismatch between demand and supply profiles. As can be seen from comparing Figs. 1 and 9, the mismatch on a monthly basis is larger in Europe, than in the USA, which is reflected in the amount of discarded electricity. The marginal value of discarded electricity for wind and solar PV for $\varphi=0.5$ is given in Fig. 10. It is significantly higher than the average values. The bent-like shape is caused by 


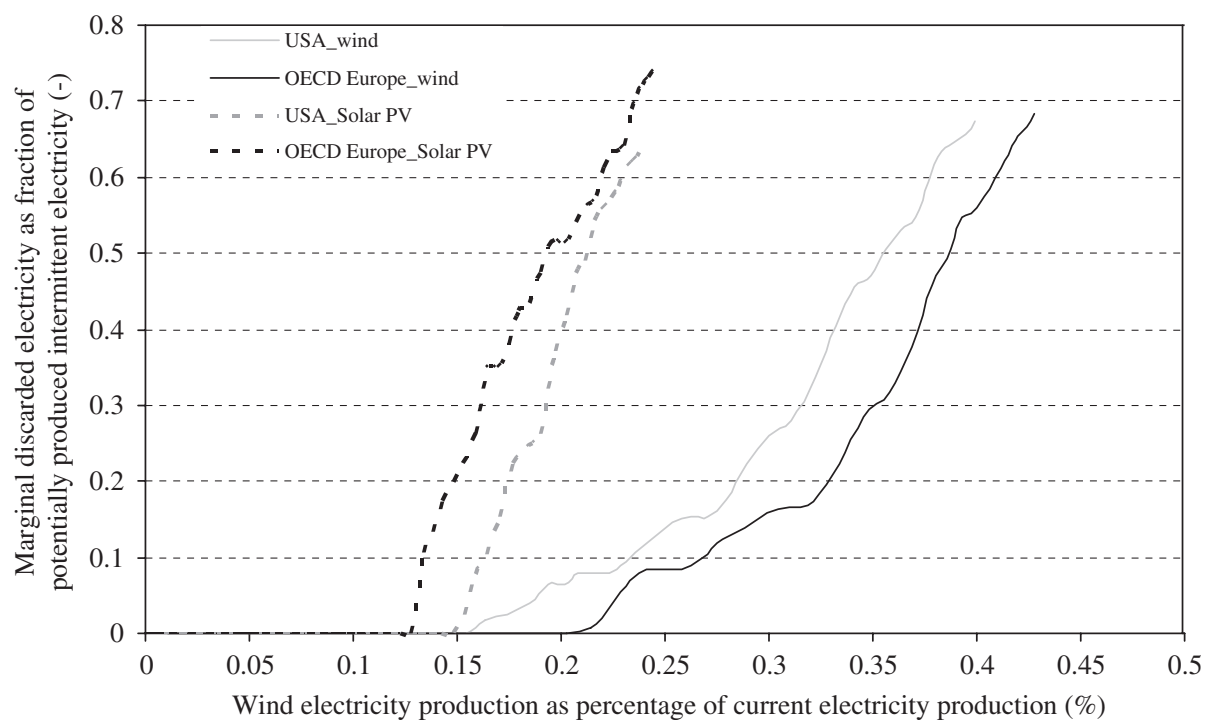

Fig. 10. Marginal value of discarded wind or solar PV electricity as function of the penetration of these renewables (on electricity basis) in the USA and OECD Europe indicated as percentage of the absorbed wind or solar PV electricity.

the discrete simulation of the Load Supply and Load Demand Curves (10 equal fractions, Fig. 7).

The results are compared with two previous studies. The set estimated by [11] for OECD Europe is derived from existing, hourly data using two different assumptions regarding the wind forecasting capability. Another literature review of discarded wind electricity as function of the wind electricity absorbed by the system in Egypt and the UK give also data for calibration and comparison [14] (see Section 3).

\subsection{Costs of wind electricity (Experiment A)}

At higher penetrations rates the wind electricity costs will decrease with cumulated experience which results in lower specific investment costs for newly installed wind turbines. In our simulation and parameter choice (Experiment A, Section 1), for $20 \%$ electricity penetration rates onwards, other effects will increase the marginal costs: depletion of favourable wind turbines sites; increase of the amount of discarded electricity, increasing need to install back-up capacity and higher spinning reserve requirements. No storage capacity is assumed to be available. The learning-by-doing induced cost decrease starts to be counteracted more and more, as Figs. 11a and b show. The cost of discarded electricity is the major factor, whereas the additional cost of spinning reserve is small and due to additional fuel costs. The cost of back-up capacity is only slowly increasing with the penetration rate due to a reduced capacity credit and increased allocated capital costs. The installed backup capacity increases from about $65 \%$ up to $90 \%$ of the installed wind capacity.

At certain levels of discarded energy, investing in storage capacity e.g., in combination with demand side management, can be a cost-effective option to reduce the cost of wind electricity. Cost for storage of electricity may be small: values of $1 \notin \mathrm{kWh}^{-1}$ for storage of wind electricity are mentioned [3]. However, costs depend on the storagetime, the storage technology and the amount of electricity that is stored. If the annual wind electricity produced is below $45 \%$ of the total system electricity produced, discarding electricity might be avoided at storage below $7 \& \mathrm{kWh}^{-1}$.

We compare our results for OECD Europe with the average values mentioned by Fellows [14] (Table 4). His estimates are based on a wind electricity production of $1200 \mathrm{TWh} \mathrm{yr}^{-1}$, which is slightly higher than our estimates of $990 \mathrm{TWh} \mathrm{yr}^{-1}$, but for similar electricity penetration levels. Fellows estimates average additional costs of about $1 \notin \mathrm{kWh}^{-1}$, compared to about $1.5 \notin \mathrm{kWh}^{-1}$ in our study. The difference stems largely from the estimated costs of discarded electricity, which in our study is higher than assumed by Fellows [14]. Furthermore, we assume higher on-site wind generation costs. The different costs for backup capacity is due to the assumption that we have allocated back-up capacity costs already for the first installed capacity of wind, whereas Fellows assumes no costs until wind electricity exceeds a penetration rate of $10 \%$.

\subsection{Fuel savings (Experiment B)}

To study the fuel savings with increasing wind electricity penetration, we use Experiment B (Section 1). The development over time of the wind power capacity and wind electricity absorbed in the system is given in Fig. 12. In the year 2010 (the year of the defined target of installed capacity), about $65 \mathrm{TWh} \mathrm{yr}^{-1}$ wind electricity is absorbed in the electricity system of the USA and about $180 \mathrm{TWhyr}^{-1}$ in the OECD European system. This corresponds to a wind electricity production of about $2 \%$ (USA) and 7\% (OECD Europe) respectively of the total system electricity production. 

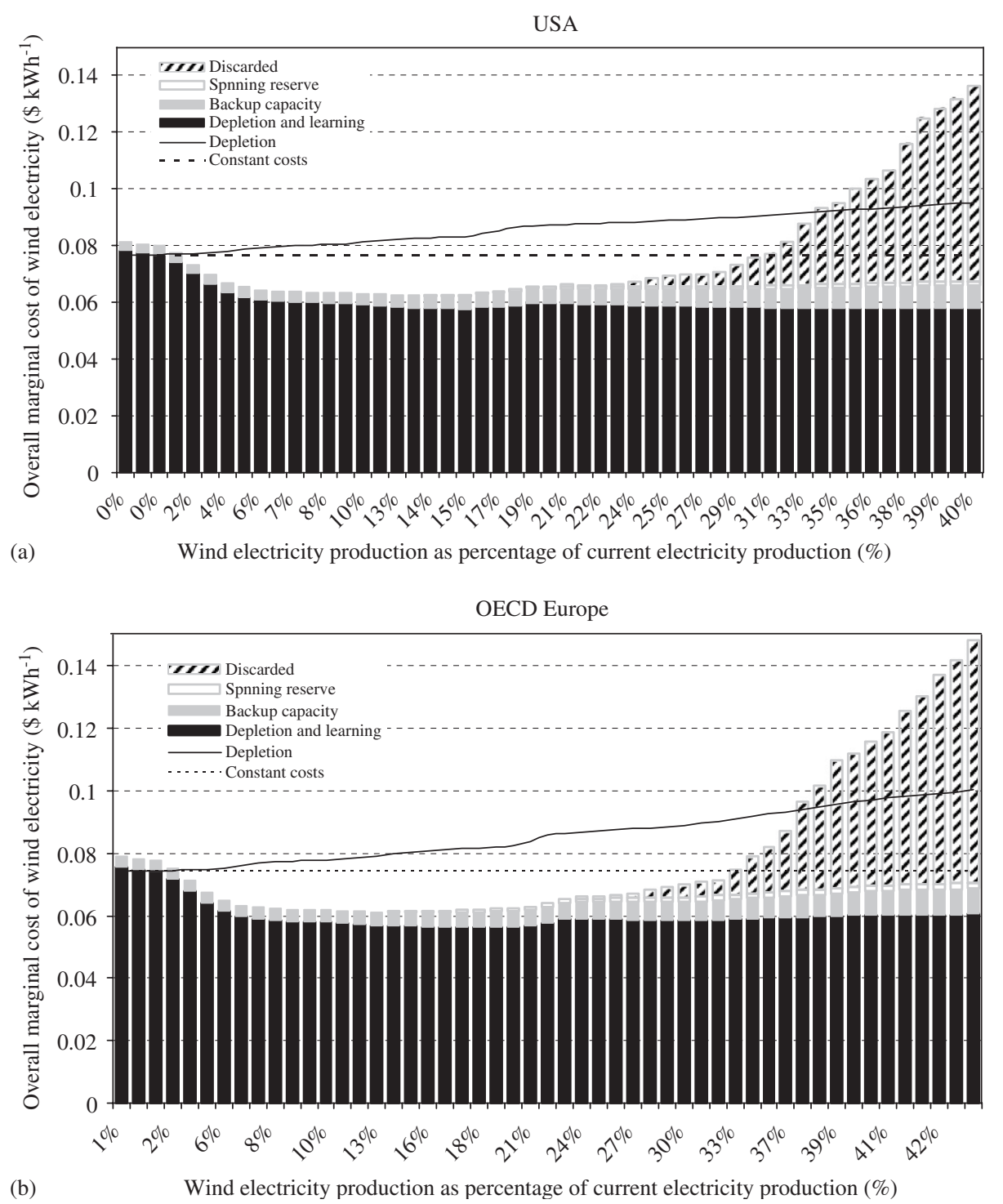

Fig. 11. (a) The marginal cost development of wind electricity in the USA with increasing wind electricity penetration subdivided in different cost components (Experiment A). (b) The marginal cost development of wind electricity in OECD Europe with increasing wind electricity penetration subdivided in different cost components (Experiment A).

Table 4

The estimated average additional costs of wind electricity at high penetration in the OECD Europe system according to [14] compared to this study

\begin{tabular}{lccc}
\hline & This study & Fellows [14]. & Unit \\
\hline Wind Electricity absorbed $^{\text {a }}$ & 990 & 1200 & $\mathrm{TWh} \mathrm{yr}^{-1}$ \\
Wind electricity penetration $^{\mathrm{a}}$ & 43 & 44 & $\%$ \\
Discarded electricity & 0.9 & 0.2 & $\phi \mathrm{kWh}^{-1}$ \\
Spinning reserve & 0.1 & 0 & $\phi \mathrm{kWh}^{-1}$ \\
Additional reserve & 0.3 & 0.6 & $\phi \mathrm{kWh}^{-1}$ \\
Additional peaking capacity & 0.3 & 0.2 & $\phi \mathrm{kWh}^{-1}$ \\
Total additional costs & $1.5^{\mathrm{b}}$ & 1.0 & $\phi \mathrm{kWh}^{-1}$
\end{tabular}

${ }^{\mathrm{a}}$ The penetration level of Fellows [14] is derived from a curve he gives on the total electricity demand in 2020.

${ }^{\mathrm{b}}$ The difference with the sum is due to rounding of the values.

Wind power penetration over the next 50 years (Fig. 12) lead to differences in estimated amounts of fuel use (Fig. 13). Initially, wind power replaces mainly old conventional coal and gas. Upon deeper penetration, wind starts to replace electricity produced in medium-load operation and increasingly in natural gas fired plants. 


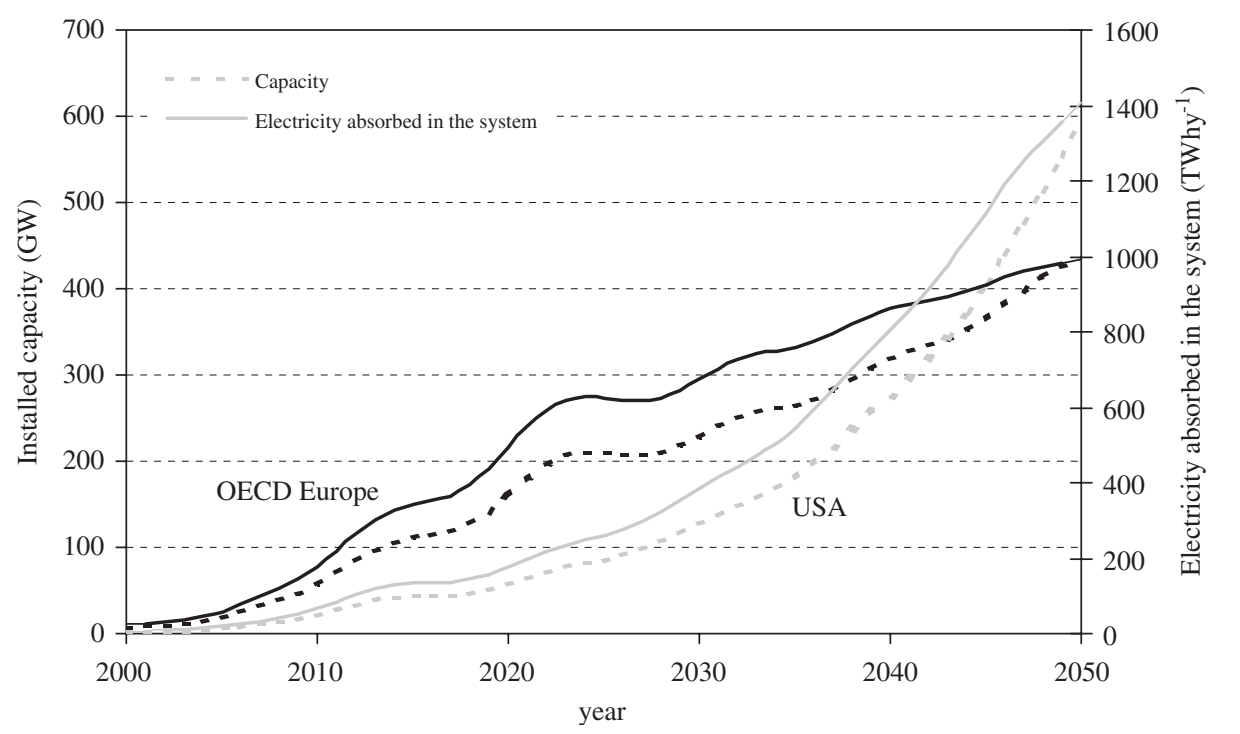

Fig. 12. The development over time of the installed wind capacity and amount of wind electricity absorbed by the systems in USA and OECD Europe (Experiment B).

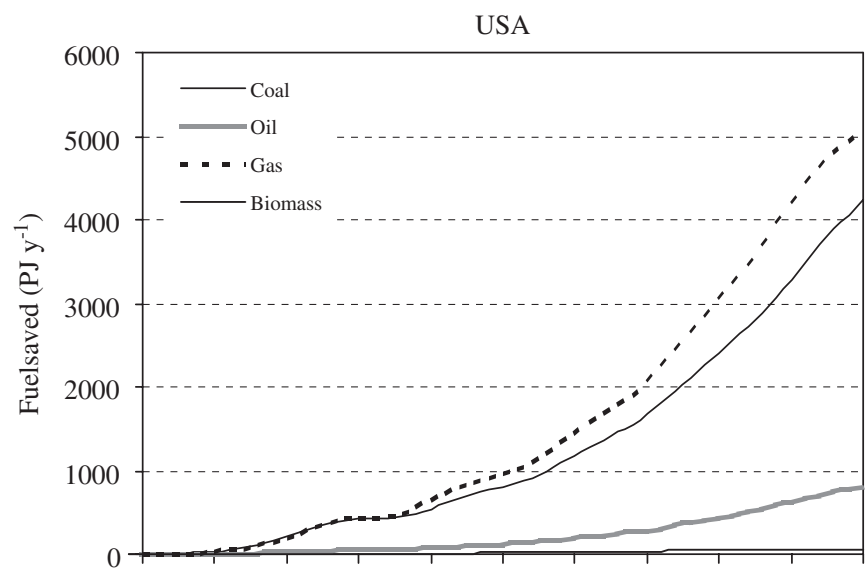

(a)

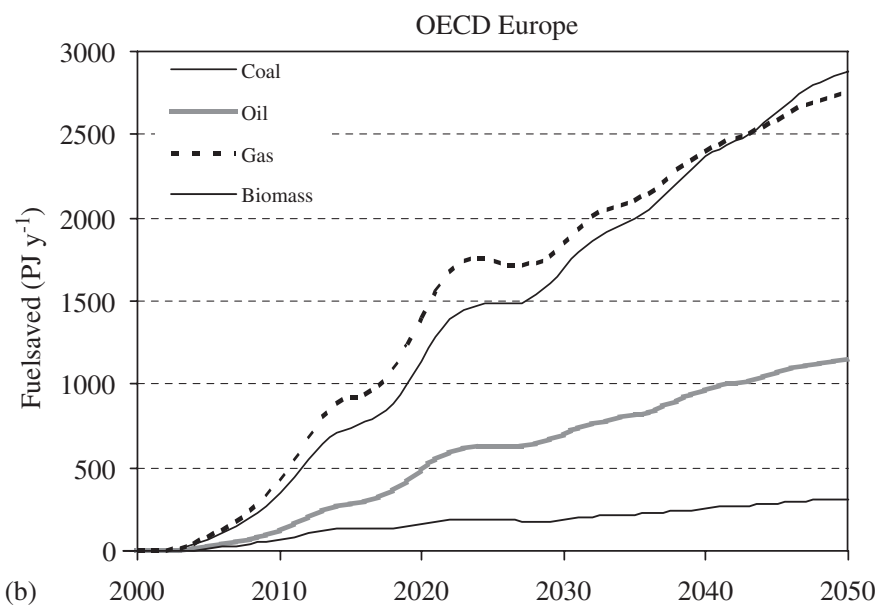

(b)

Fig. 13. Fuel use avoided due to wind power if wind capacity increases to about 38\% (USA) - 43\% (OECD Europe) penetration in 2050 in Experiment B.

\subsection{Potential $\mathrm{CO}_{2}$ abatement costs (Experiment B)}

In view of climate change, an interesting indicator to compare different mitigation option is the $\mathrm{CO}_{2}$ abatement costs. To this purpose we first calculate the electricity production costs of the system with and without wind penetration for the timeframe 2000-2050. These are combined with the $\mathrm{CO}_{2}$ emissions avoided as a result of fuels savings (Fig. 13), to calculate the simulated $\mathrm{CO}_{2}$ abatement costs. ${ }^{16}$ The result is shown in Fig. 14. Note that constant fuel and capital costs of the fossil-fired plants have been assumed and hydro and nuclear power are exogenously set. At first, abatement costs decline due to technological learning to about $33 \$$ per ton $\mathrm{CO}_{2}$ avoided

\footnotetext{
${ }^{16}$ The $\mathrm{CO}_{2}$ emissions abatement costs are calculated as follows: (simulated $\Delta \mathrm{kWh}$ generation costs) $/$ simulated $\Delta \mathrm{CO}_{2}$ emissions).
}

in the USA and to a level of about $14 \$$ per ton $\mathrm{CO}_{2}$ avoided in OECD Europe. In 2010, in OECD Europewith an installed capacity of $75 \mathrm{GW}$ - emission of about $76 \mathrm{Mton} \mathrm{CO}_{2}$ can be avoided at average costs of about $18 \$$ ton per $\mathrm{CO}_{2}$. This is about $26 \%$ of the total target of $\mathrm{CO}_{2}$ abatement according to the Kyoto protocol [50]. Because in our experiment wind electricity penetrates faster in OECD Europe than in the USA (see Fig. 12), the $\mathrm{CO}_{2}$ abatement costs increase more rapidly too. These costs may be reduced significantly if storage of discarded electricity is applied (Fig. 11). Comparing our results with those presented by Fellows [14] (Fig. 14), it is seen that his abatement cost estimates tend to be higher at the end, but lower for the first 100-200 Mton of abated $\mathrm{CO}_{2}$. The differences originate mainly from our higher on-site wind electricity costs and a relatively larger replacement of coal/ oil instead of natural gas. Negative costs, as indicated by Fellows [14] for OECD Europe at low penetration, were 


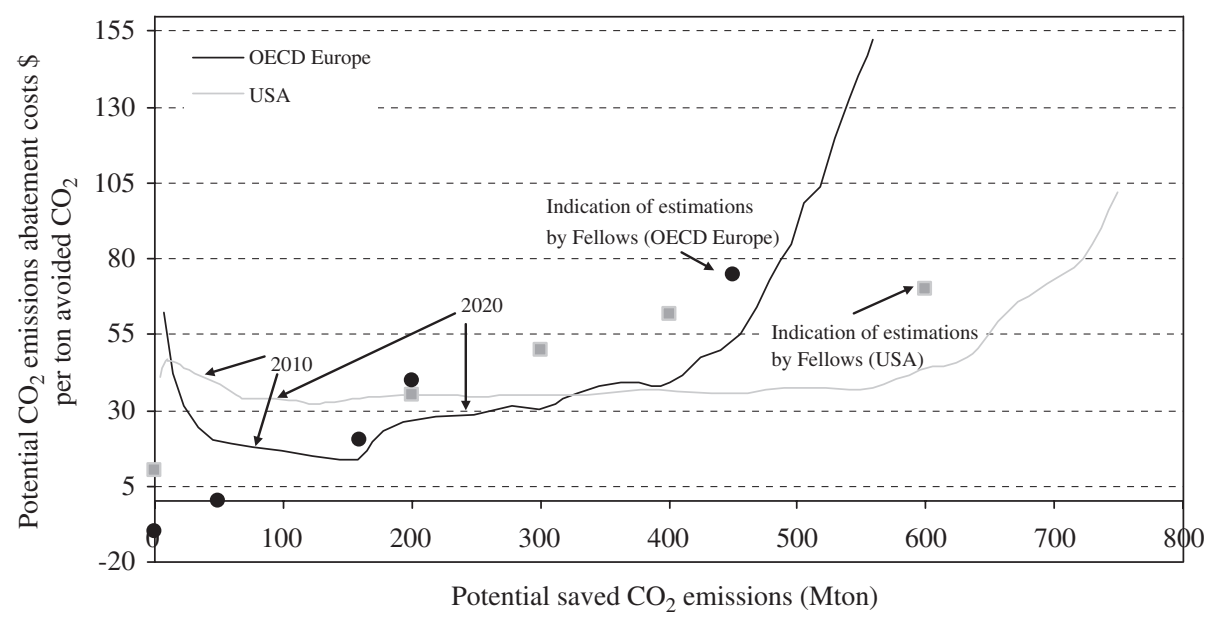

Fig. 14. The potential $\mathrm{CO}_{2}$ abatement cost for wind electricity with increasing wind power penetration (Experiment B). For comparison, also results of Fellows [14] are shown.

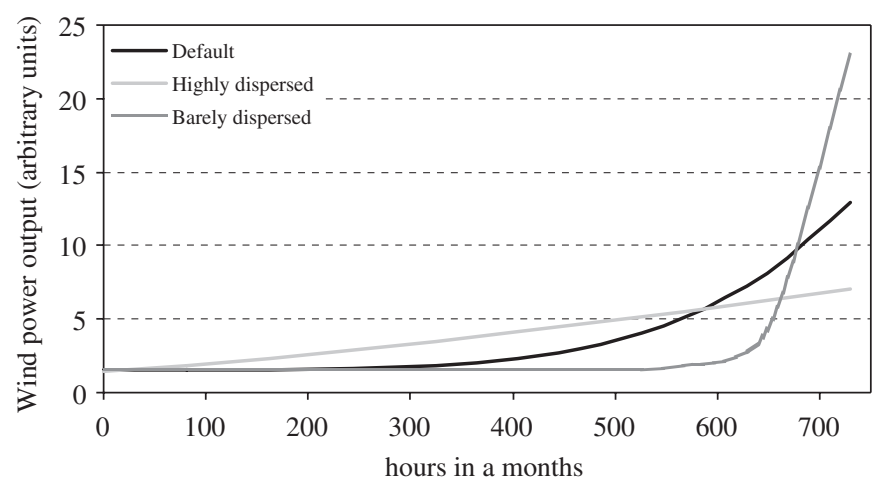

Fig. 15. Assumptions regarding the monthly load supply curve of wind power resulting from the assumed geographical dispersion, as used in the sensitivity analysis.

also concluded by [50]. This can be explained mainly by the lower wind turbine electricity costs assumed, i.e. about a factor 2 lower compared to our values for the USA (Fig. 15).

\section{Sensitivity analysis (Experiment B)}

Our results depend of course on the assumptions and constrained setting of the experiments. Therefore, we conduct a one-factor sensitivity analyses to study how sensitive they are for the following: (1) the 'mismatch coefficient' $(\varphi)$; (2) the technical potential of wind electricity production; (3) the Load Supply Curve of wind electricity production within a month; (4) the progress ratio as a measure for technological learning and (5) the multiplier that accounts for the additional on-site costs for administration, etc. (see Section 4.9). The results are shown in Fig. 16.

\subsection{The 'mismatch coefficient'}

The default value of $\varphi$ is 0.5 . For the sensitivity analysis, we varied this value from 0.3 to 1.0 (Fig. 9). The results show that this parameter is important: lower $\varphi$-values cause a disproportional increase in discarded electricity, and hence in wind electricity and $\mathrm{CO}_{2}$ emissions abatement costs. Evidently, more research is needed into the value of this parameter and on innovations to keep it as high as possible.

\subsection{Depletion: the technical potential}

The technical potential used as default is based on assumptions regarding the power density of the turbines $\left(\mathrm{MW} \mathrm{km}^{-2}\right)$ and the land-use suitability [2]. These assumptions are to some extent arbitrary and dependent on social values. Therefore, four extreme situations for the technical potential with extreme settings of the power density and the land-use suitability have been analysed. The lowest and highest technical potential were for the USA $4 \times 10^{2}$ to $515 \times 10^{2} \mathrm{TWh} \mathrm{yr}^{-1}$ and for OECD Europe $0.8 \times 10^{2}-104 \times 10^{2} \mathrm{TWh} \mathrm{yr}^{-1}$ as compared to default values of $206 \times 10^{2}$ (USA) and $41 \times 10^{2} \mathrm{TWh} \mathrm{yr}^{-1}$ (OECD Europe). In case of low technical potential, all available sites are exploited including the sites with rather low wind speed. Consequently, the overall wind electricity costs increase mainly because of depletion of the available wind resources and full use of the potential takes place within the timeframe considered in both regions. The opposite occurs with high technical potentials. From sites with high wind speeds, more electricity can be produced as there is more land available and the power density is higher, resulting in a higher average load factor. This also implies higher discarded amounts of electricity. Overall, in our setting, a higher technical potential than the default value has only a marginal net impact on the wind electricity penetration rate and overall wind electricity costs. 

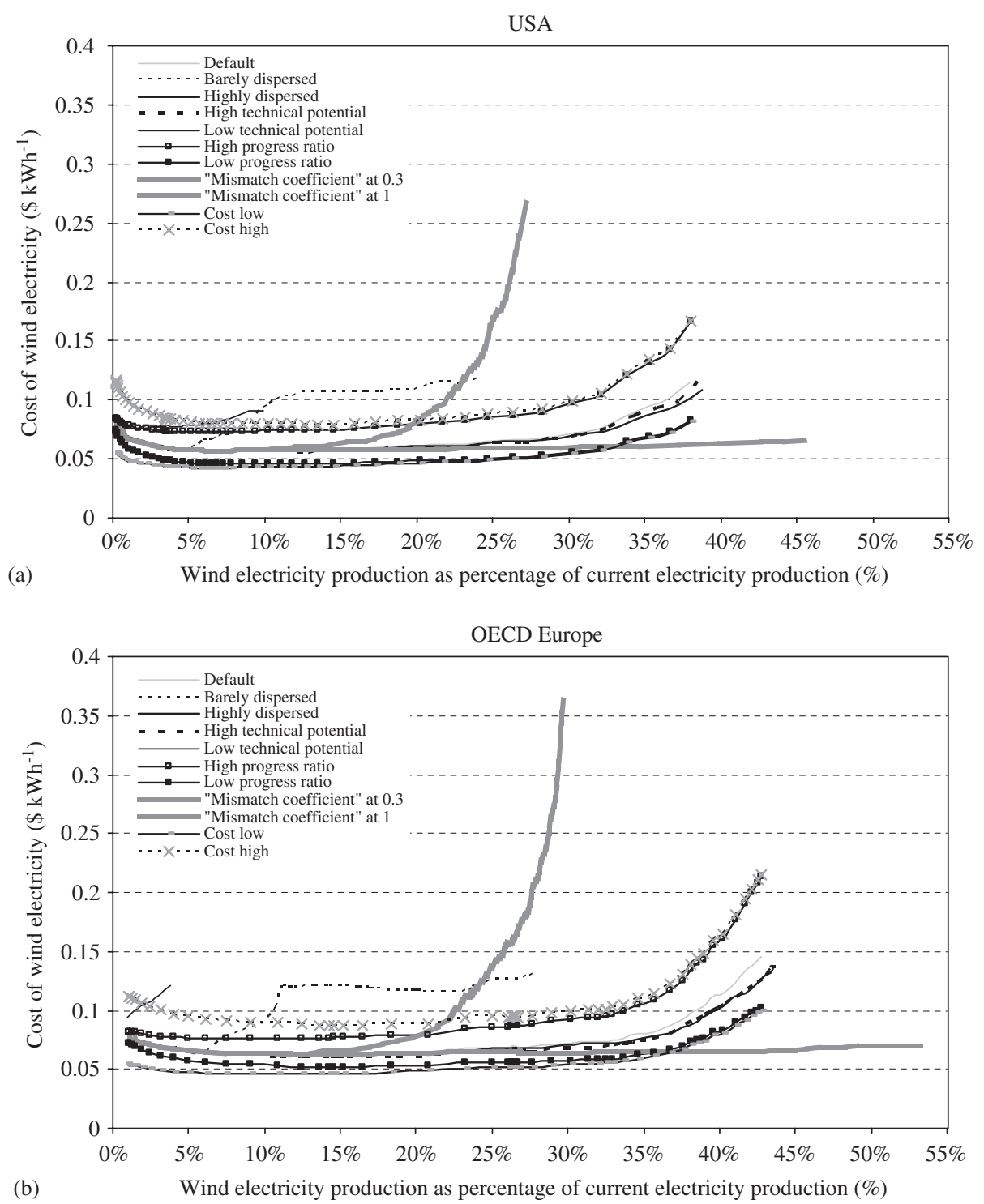

Fig. 16. Sensitivity analysis for four parameters influencing the electricity penetration and cost of wind electricity if wind capacity increases in the USA and OECD Europe from the year 2000 to 2050 (Experiment B).

\subsection{The load supply curve of wind electricity; geographical dispersion}

If wind turbines are placed far apart in areas with different wind regimes, which is likely within the two regions considered, the monthly load supply curve of the wind power supply is smoothened (Section 3). We assume two extremes, shown in Fig. 15. In general, if wind farms are barely dispersed, there is more wind electricity discarded and this occurs already at low electricity penetration rate compared to the default situation. This is also indicated in Fig. 7. Thus less electricity is absorbed in the system and overall wind electricity costs increase. The opposite occurs if wind farms are geographically more dispersed. This factor is related to ad (1) and ad (2). If the wind turbines are more geographically distributed it can be expected that its technical potential is lower (increasing wind electricity costs), but that its mismatch is also smaller (reducing wind electricity costs). What the overall impact of this factor is, cannot be concluded using this statis sensitivity analysis.

\subsection{Technological learning: declining capital costs}

For the sensitivity analysis we varied the progress ratio from 0.85 to 0.95 , around the default value of 0,9 . This leads to lower, resp. higher wind turbine electricity generation costs. The electricity absorbed by the system is identical to the default situation.

\subsubsection{Costs multiplier for additional on-site costs}

As is explained in Section 4.9, we have multiplied our static cost-supply curve with a factor that accounts for costs like overhead, administration, etc. We have varied the 
default lowest cost values, of about $5 \phi \mathrm{kWh}^{-1}$ (cost low) to $11 \notin \mathrm{kWh}^{-1}$ (cost high). This linearly changes the overall wind electricity cost and influences the cost of discarded electricity. If overall production costs of wind electricity are lower, the additional costs due to discarded electricity are also lower.

\section{Discussion}

Our analysis is based on the use of a highly aggregated (semi) dynamic model using LDC at a monthly level. The analysis was done using a constant demand for electricity. This is a significant limitation compared to analyses of the development and operation of present and future national electricity systems at hourly basis. The impact of these constraints needs to be analysed further.

We have analysed discarded electricity using a 'mismatch coefficient', which accounts in a generalised way for interconnection, transmission capacity and load following capabilities. The value of the coefficient has not been related to the load following capacity of the park, and the 'mismatch coefficient' is kept constant over the analyses. This is a simplification as it can be influenced by the installation of better load following capacities, e.g., peaking plants. Furthermore, we have treaded Europe and the US in a similar, deriving our "mismatch factor" for the European situation. The grid in the USA consists of three independent grids. For Europe the interconnection depends largely at country scale. Whereas the Nordic regions are highly connected, Spain is often considered an Island when it comes to the grid. This affects the value of the 'mismatch factor' and therefore the amount of discarded electricity. More detailed study on the interconnection and the mismatch is required at a regional level.

All scenarios on the future electricity system assume an increase in electricity demand. Our assumption of constant demand after the year 2000 would imply that we overestimate the amount of discarded wind electricity in our study and consequently, also the overall wind electricity costs and $\mathrm{CO}_{2}$ emissions abatement costs.

More in general, the aggregation level of our analysis and simulations does not account for many of the local and regional features of reliable and cost-effective electricity systems-leaving aside the complications and consequences of liberalisation. The approach is based on the concept of centralised planning of investments and operational strategy. In an increasingly liberalised and privatised electricity sector, this may not be a good representation, although an RTO-like structure ${ }^{17}$ might approximate the centralized planning. The operation strategy is not applied at a whole region or country, but to smaller units. This reduces the load following capacity of the system. Furthermore, assumptions like that hydropower capacity is dispatched after wind power capacity are important as this influences the amount of discarded electricity.

\footnotetext{
${ }^{17}$ An Regional Transmission Organisation.
}

The advantages of the storage capabilities of hydropower are also not taken into account, which overestimates the amount of discarded electricity.

Keeping fuel and capital costs of conventional power plants constant will also affect our results of the system costs analysed, and thus on the $\mathrm{CO}_{2}$ emissions abatement cost estimates. Furthermore, one may expect different market shares of power plants if fuel and capital cost developments are taken into account.

The forced penetration paths that have been constructed are of course hypothetical, although linked to targets and compared to not unrealistic historical growth rates. However, we have not assumed simultaneous improvements of the electricity system. One may expect that if wind (or solar PV) is forced in the system (e.g., due to stringent climate policy) more storage capacity and transmission capacity will be installed also, reducing the amount of discarded electricity.

The assumed costs of wind electricity in the year 2000 are based on static cost-supply curves of wind electricity and on additional estimates on the costs of administration, insurance, distribution, etc. These additional estimates are based on the Dutch situation, of course, these figures may not apply to other countries or on a regional scale. Other values for these costs do affect the cost-supply curves of wind electricity in absolute numbers, but not the conclusions regarding costs reductions and cost increase as function of the supply. $\mathrm{CO}_{2}$ emissions abatement costs may of course be different.

We use a simple method to estimate the additional transmission costs. The estimated load centres are based on population density only, which may not reflect correctly the industrial electricity. Also we have not included costs for transmission capacity increases; the assumptions made are subject for discussion and may cause variation of the transmission costs. This may vary the cost of wind electricity with a few dollarcents perkWh. This will however not cause major changes to the conclusions.

We have not included the potential of offshore wind electricity. This underestimates the technical potential of $\mathrm{CO}_{2}$ emission reduction and overestimates the cost increase caused by depletion of the wind resources. Further analyses including this electricity source are especially of importance for OECD Europe.

During the experiments a global learning curve for intermittent capacity was used. However, the rest of the world was assumed to have zero wind (and solar PV) capacity. This causes an underestimation of the learning rate and consequently an overestimation of the electricity costs compared to a situation where the rest of the world also invests in renewables.

Finally, we should mention neglecting storage capacity. It was illustrated that investments in storage capacity could reduce the discarded electricity significantly as we have shown in Section 5. Also using hydro power in combination with wind electricity may be an efficient and cost effective storage option that could not be explored in this 
analysis due to the time and geographical scale of this study.

These remarks have to be taken into account when considering the results of our study. However, our approach enables to focus on the impact of independent parameters. In a full dynamic model these investigations would not have been possible. Furthermore, the aggregation level used in this study allows analyses at the scale of the USA and OECD Europe as one system. This approach can therefore be used in global or regional energy models such as TIMER 2.0, to study for instance the cost of $\mathrm{CO}_{2}$ emission abatement under different power regimes and to simulate the competitiveness of renewables in a dynamic system.

\section{Summary and conclusions}

In this study we have explored the dynamics of electricity production and associated costs of onshore wind (and solar PV) electricity with increasing shares in the USA and European electricity systems. Also the amount of fuels saved and the abatement costs of $\mathrm{CO}_{2}$ emissions have been analysed. The analyses have been done under constraining assumptions, which limits the conclusions to be drawn but may improve the understanding of the factors that influence the cost of wind electricity.

With increasing penetration wind production costs may further fall thanks to technological learning. However, this effect is counteracted by:

1. The depletion effect, accounting for a transition to sites with lower wind speeds and less solar irradiance. This effect may cause a cost increase of $25-50 \%$, counteracting the larger part of the expected gains from technological learning.

2. Back-up capacity, accounting for the additional capital costs that have to be made to maintain system reliability.

3. Discarded electricity, due to a system failure to absorb all wind or solar PV electricity produced, given the (estimated) supply and demand fluctuations and generation and transmission capabilities. At about 20\% wind electricity produced as percentage of total current electricity produced, about $750 \mathrm{TWh} \mathrm{yr}^{-1}$ produced in the USA and $500 \mathrm{TWh} \mathrm{yr}^{-1}$ in OECD Europe wind electricity is discarded. If wind electricity production exceeds about $30 \%$ of current electricity produced, discarded electricity is found to be the most significant factor for cost increase, accounting for $50 \%$ of the overall wind electricity cost. Options to store the discarded electricity, which could reduce these costs, are not considered.

The use of wind electricity would mainly avoid use of natural gas and coal in both regions. However, the $\mathrm{CO}_{2}$ emission abatement costs differ in both regions due to the more rapid wind electricity cost increase in OECD Europe.
Lowest levels of $\mathrm{CO}_{2}$ abatement costs are found at about $15-35 \$$ ton $\mathrm{CO}_{2}^{-1}$.

The results are sensitive to the technical potential in the region and to system parameters, such as transmission capacity and geographical dispersions of installed wind and solar PV capacity within a region. The technical potential is assumed to depend mainly on social- and geographical factors like the suitable area and the power density of the wind turbines. If social acceptance is low, the technical potential is low and wind can barely penetrate. On the other hand, wind could become attractive in terms of electricity production contribution and costs and $\mathrm{CO}_{2}$ abatement if social acceptance for wind turbines is high and the system is technically optimal, with high transmission and interconnection capacity and sufficient low-cost storage capacity.

\section{Acknowledgements}

We are grateful to the technical support of Rineke Oostenrijk (RIVM) for the estimation of the transmission distances and to Peter Vaessen (KEMA) for the information of transmission costs.

\section{References}

[1] Hoogwijk M. On the global and regional potential of renewable energy sources. Utrecht: Utrecht University; 2004.

[2] Hoogwijk M, de Vries HJM, Turkenburg WC. Assessment of the global and regional geographical, technical and economic potential of onshore wind energy. Energy Econom 2004;26:889-919.

[3] Turkenburg WC. Renewable energy technologies. In: Goldemberg J, editor. World energy assessment. Washington, DC: UNDP; 2000. p. $220-72$.

[4] van der Zwaan B, Rabl A. Prospects for PV: a learning curve analysis. Solar Energy 2003;74:19-31.

[5] Danish Wind Industry Association. Wind energy policy in Denmark Status: Danish Wind Industry Association. Copenhagen, 2002. See also:〈www.windpower.org 〉.

[6] Bundesverband Wind Energie. German wind power still flying high. Osnabrück, 2003.

[7] Anonymous. Grid stability and expansion challenges: Wind Power Monthly News Magazine, 2002.

[8] Johansson TB, Kelly H, Reddy AKN, Williams RH. Renewable fuels and electricity for a growing world economy - defining and achieving the potential. In: Johansson TB, Kelly H, Reddy AKN, Williams RH, editors. Renewable energy: sources for fuels and electricity. Washington, DC: Island Press; 1993. p. 1-71.

[9] Lazarus M. Towards a fossil free energy future. Boston: Stockholm Environment Institute; 1993240.

[10] Nakicenovic N, Swart R. Special report on emission scenarios. Cambridge: Cambridge University Press; 2000.

[11] Giebel G. On the benefits of distributed generation of wind energy in Europe. Oldenburg: University of Oldenburg, Department of Physics; 2000.

[12] Grubb MJ. The economic value of wind energy at high power system penetrations: an analysis of models, sensitivity and assumptions. Wind Eng 1988;12(1):1-26.

[13] van Wijk A. Wind energy and Electricity Production. Utrecht: Utrecht University; 1990.

[14] Fellows A. The potential of wind energy to reduce carbon dioxide emissions. Glasgow: Garrad Hassan; 2000. 
[15] de Vries BJM, van Vuuren, DP, Janssen M, den Elzen. M. The Targets IMage Energy model Regional (TIMER), Technical documentation. Bilthoven: MNP; 2002.

[16] Van Vuuren DP, de Vries HJM, Hoogwijk M, Ruijven B. TIMER 2.0-Technical documentation. Bilthoven: MNP; 2005.

[17] AWEA. Wind energy and climate change. Washington, DC: AWEA; 1998. See also 〈www.awea.org >.

[18] EWEA. 86 Million European to get power from the wind by 2010 - wind industry sets bigger target for Europe. Brussel: EWEA; 2003.

[19] New M, Hulme M, Jones P. A 1961-1990 mean monthly climatology of global land areas. Norwich: Climate Research Unit, University of East Anglia; 1997.

[20] New M, Hulme M, Jones P. Representing twentieth century spacetime climate variability, Part I: development of a 1961-91 mean monthly terrestrial climatology. American Meteorological Society 1999:820-56.

[21] IMAGEteam. The IMAGE 2.2 implementation of the SRES scenarios: a comprehensive analysis of emissions, climate change and impacts in the 21st Century. Bilthoven: MNP; 2001.

[22] Kurokawa K. Energy from the desert-feasibility of very large scale photovoltaic power generation (VLS-PV) systems. London: James \& James; 2003.

[23] Brower MC, Tennis MW. Catching a steady breeze: putting wind power to work on electric utility systems. Electricity J 1995: 32-41.

[24] Vaessen PTM. Indicative costs of electricity transmission. Personal Communication. Arnhem: KEMA; 2003.

[25] Betcke J. High voltage direct current transmission: wind by wire. Utrecht: Utrecht University; 1995.

[26] Pantaleo A, Pellerano A, Trovato M. Technical issues on wind energy integration in power systems: projections in Italy. In: EWEA, editor. 2003 European Wind Energy Conference, Madrid, 2003.

[27] Wan Y-H, Parsons BK. Factors relevant to utility integration of intermittent renewable technologies. Golden: National Renewable Energy Laboratory; 1993.

[28] Alsema EA, van Wijk AJM, Turkenburg WC. The capacity credit of grid-connected photovoltaic systems. In: Fifth E.C. Photovoltaic solar energy conference. Athens: D. Reidel Publisher Company; 1983

[29] Milligan MR. Modeling utility-scale wind power plants part 2: Capacity credit. Golden, USA: National Renewable Energy Laboratory; 2002.

[30] Gardner P, Sodin H, Higgins A, Mc Goldrick S. The impacts of increased levels of wind penetration on the electricity systems of the Republic of Ireland and Northern Ireland. Glasgow: Garrad Hassan and Partners; 2003.
[31] Giebel G. Equalizing effects of the wind energy production in Northern Europe determined from reanalysis data. Roskilde: Risø; 2000.

[32] FGW, ISET. Increasing the penetration of wind energy in the European electricity network. Fordergesellschaft Windenergie, Institut fur Solar Energieversorgungstechnik; 2000. p. 47.

[33] Brand AJ, Kok JK. Aanbodvoorspeller duurzame energie. Petten: ECN; 2003.

[34] Anonymous. E.on to use forecasting model for predicting wind. Wind Power Monthly News Magazine 2003.

[35] Anonymous. Wind weakening system security - Spain's isolated grid. Wind Power Monthly News Magazine 2002.

[36] Argote L, Epple D. Learning curves in manufacturing. Science 1990;247(February):920-4.

[37] McDonald A, Schrattenholzer L. Learning curves and technology assessment. International Journal of Technology Management 2002;23(7/8):718-45.

[38] Neij L. Cost dynamics of wind power. Energy 1999;24:375-89.

[39] IEA/ OECD. Experience curves for energy technology policy. Paris: IEA/OECD; 2000.

[40] Junginger M, Faaij A, Turkenburg WC. Global experience curve for wind farms. Energy Policy 2005;33(2):277-81.

[41] Harmon C. Experience curves of photovoltaic technology. Laxenburg: IIASA; 2000

[42] Parente V, Goldemberg J, Zilles R. Comments on experience curves for PV modules. Progress in photovoltaics research and applications 2002;10(8):571-4.

[43] OECD/ IEA. Energy statistics \& balances. Paris: IEA/OECD; 2002.

[44] IEPE, Technology improvement dynamics database-developed under the EU-DG Research Sapient project, Grenoble: IEPE; 1998. p. 40.

[45] Van Sambeek EJW, de Lange TJ, Ruijgrok WJA, Pfeiffer EA Onrendabele toppen van duurzame elecktriciteitsopties. Petten: ECN; 2003.

[46] BTM. International Wind Energy Development-World Marke Update 2000. BTM Consult Aps, 2001.

[47] Anonymous. Tararua wind farm at top of output league table. Wind Power Monthly 2003.

[48] Anonymous. Impressive capacity figures for Minnkota in US. Wind Power Monthly 2002.

[49] den Elzen M, Both S. Modelling emissions trading and abatement costs in FAIR 1.1 Case study: the Kyoto Protocol under the BonnMarrakesh Agreement. Bilthoven: RIVM; 2002.

[50] Sims REH, Rogner H-H, Gregory K. Carbon emission and mitigation cost comparison between fossil fuel, nuclear and renewable resources for electricity generation. Energy Policy 2003;31:1315-26. 